\title{
Símbolos geométricos en la CerámicA de IZAPA, Chiapas
}

\author{
Alla Kolpakova
}

Resumen: El artículo aborda el amplio conjunto de símbolos geométricos (puntos, líneas, triángulos, círculos, etcétera) elaborados sobre la cerámica proveniente del sitio arqueológico de Izapa, Chiapas. Dichos símbolos tienen una importancia especial para el entendimiento de la historia de los orígenes de la civilización en el sureste de Mesoamérica. Paradójicamente, este material no ha recibido la atención necesaria en la historiografía sobre la región. En nuestro trabajo distinguiremos cuáles símbolos se suelen encontrar en la cerámica mencionada y definiremos cuáles de ellos habrían sido los primigenios y cuáles los más frecuentes. El propósito final es dilucidar, con auxilio de diversas fuentes comparativas, los posibles significados "básicos" que los antiguos alfareros de Izapa otorgaban a los símbolos que imprimían en su cerámica.

Palabras clave: símbolos geométricos, cerámica, Izapa, Mesoamérica.

Enviado a dictamen: 20 de enero de 2009

Aprobación: 11 de mayo de 2009

Revisiones: 1

Alla Kolpakova, licenciada en Filología por la Facultad de Filología de la Universidad Estatal de Voronezh, Rusia; temas de especialización: mitología mundial, simbología antigua mesoamericana, folklor. Correo electrónio: lunchikp@mail.ru..
Abstract: The article tackles the wide set of geometric symbols (points, lines, triangles, circles, etc.) prepared on the ceramics originated from the archaeological place of Izapa, Chiapas. The abovementioned symbols have a special importance for the understanding of the history of the origins of the civilization in the southeast of Mesoamerica. Paradoxically, this material has not received the necessary attention in the historiography on the region. In our work, we will distinguish which symbols are usually in the mentioned ceramics. We will define which of them would have been original and which the most frequent. The final intention is to elucidate, with help of diverse comparative sources, the possible "basic" meanings that the ancient Izapa potters were granting to the symbols that they were printing on his ceramics.

Key words: geometric symbols, ceramics, Izapa, Mesoamerica.

\section{Introducción}

l presente trabajo aborda el amplio conjunto de símbolos geométricos (puntos, líneas, triángulos, círculos, etcétera) elaborados sobre la cerámica proveniente del sitio arqueológico de Izapa, Chiapas. En las siguientes líneas distinguiremos cuáles símbolos se suelen encontrar en la cerámica mencionada y definiremos cuáles de ellos fueron los primigenios y cuales los más frecuentes. También observaremos su evolu- 
ción formal a través del tiempo. El propósito final es dilucidar, con auxilio de diversas fuentes comparativas, los posibles significados que los antiguos alfareros de Izapa imprimían en los símbolos de su cerámica. De esta manera profundizaremos también en la cosmovisión de los antiguos habitantes de este sitio.

Cabe señalar aquí que el presente estudio se debe a que los símbolos geométricos sobre la cerámica de Izapa prácticamente nunca han sido abordados en los estudios sobre el lugar. Los diversos trabajos iconográficos sobre este sitio, centrados principalmente en las obras monumentales como las estelas, ${ }^{1}$ por lo general han dejado de lado el fenómeno de los símbolos elaborados sobre la cerámica. Es de suponer que estos materiales ni siquiera han sido publicados (con excepción del trabajo de Susanna Ekholm de 1969). Este vacío es lamentable pues si consideramos, como Rafael Girard, que las formas primigenias de los motivos simbólicos que se desarrollarían más tarde en la cultura maya clásica se encuentran en la región del Pacífico, entre Chiapas y Guatemala (Girard, 1949: 1084), entonces los símbolos de la cerámica de Izapa adquieren una importancia especial para el entendimiento de la historia de los orígenes de la civilización en el sureste de Mesoamerica. Además del hecho de que Izapa, que es uno de los sitios más antiguos en Chiapas (ocupado con diversas intensidades durante un lapso que sobrepasa los 2,500 años), es también uno de los que tuvo mayor influencia sobre la cultura maya (Lowe, Lee y Martínez E., 2000: 153).

El sitio arqueológico de Izapa está justamente localizado a unos cuantos kilometros al oeste de la frontera de Mexico con Guatemala y a 35 kilómetros del Oceano Pacífico, sobre el margen occidental del pequeño río Izapa (Figura 1). El terreno boscoso donde se localiza Izapa estuvo ocupado por una población que usó la cerámica ya desde épocas tempranas, al parecer poco después del 1,500 a. C. (Lowe, Lee y Martínez E., 2000: 25, 87, 154, 157). En la cerámica los antiguos alfareros registraron diversos símbolos utilizando varias técnicas de decoración como el estampado, la impresion, la incisión, la pintu- ra, el punteado, el pastillaje, el modelado y el grabado (Ekholm, 1969; Lee, 1973; Lowe, Lee y Martínez E., 2000).

Con el objeto de asegurar una visión más completa sobre el conjunto de los símbolos en la cerámica de Izapa, en este trabajo abordaremos la secuencia cerámica completa de este sitio. ${ }^{2}$ Dado que a partir de fase Jocotal (ca. 1000-850 a. C.) las decoraciones en la cerámica empiezan a ser cada vez más complejas, sólo abordaremos aquellas piezas que muestren los símbolos geométricos independientes o elementales objetos del presente trabajo (puntos, líneas, triángulos, círculos, etcétera). Dichos símbolos son al final agrupados en una tabla comparativa general para su mejor visualización (Figura 25).

Para la interpretación del significado de los símbolos recurriremos al libro Mith and Symbol del especialista israelí Arien Golan, quien realizó un importante trabajo sobre los símbolos de los pueblos del mundo y determinó los significados más antiguos de las figuras geométricas, usando como fuente principal la cerámica. Buscaremos verificar esos significados en los símbolos de la cerámica de Izapa. Seremos testigos de cómo en las intepretaciones de los símbolos coinciden con Golan estudiosos de la cultura mesoamericana tales como Terrence Grieder y Rafael Girard, cuyos trabajos serán ampliamente utilizados en este estudio. La obra de Girard es importante en particular pues sus interpretaciones de los símbolos están basadas en observaciones etnográficas hechas entre los mayas chortíes de Guatemala de mediados del siglo XX. Además realizaremos comparaciones con el material iconográfico de Izapa que corresponda, en particular con sus estelas. ${ }^{3}$ También usaremos algunos ejemplos de la escultura monumental de otros sitios contemporáneos a Izapa.

Cabe aquí subrayar que lo que nos interesa al abordar la cerámica de Izapa es encontrar los símbolos primigenios y tratar de determinar su significado "básico", es decir, aquel significado formado durante los tiempos más antiguos. En ese sentido tenemos bien claro que la 
distancia entre la antiguedad de Izapa y las creencias contemporaneas es bastante amplia. Efectivamente, con el paso del tiempo los símbolos pueden cambiar o aceptar nuevas interpretaciones y significados (Golan, 1981). Sin embargo, si aceptamos la teoría de que "no importa cómo cambien las interpretaciones y asociaciones relacionadas conel símbolo, lo que permanece es el arquetipo de su significado, el antecedente elemental" (Bauer, Dümotz y Golowin, 1998: 10), entonces estaremos en condiciones de rastrear el significado original de los símbolos de la cerámica de Izapa ya que los cambios habrían ocurrido dentro del patrón "basico" del significado.

El material cerámico que utilizaremos en este trabajo proviene de la Fundación Arqueológica Nuevo Mundo A. C. (NWAF), cuyos responsables generosamente nos permitieron trabajar con las piezas. En total revisamos alrededor de 2,500 tepalcates entre los cuales más de 450 tenían símbolos. Ejemplos de tepalcates con los símbolos más representativos son expuestos en ilustraciones para cada periodo que acompañan al presente artículo. Debemos señalar que en algunas fases los tepalcates con símbolos son escasos y en la fase Hato no se encontró ningun ejemplo. Es por eso que recurrimos a las fotos publicadas en los trabajos Mound 30a and the Early Preclassic Ceramic Sequence of Izapa, Chiapas, Mexico de Susana Ekholm (1969), Secuencia de fases postformativas en Izapa, Chiapas, Mexico de Thomas Lee (1973) e Izapa: Una introducción a las ruinas y los monumentos de Gareth Lowe, Thomas Lee y Eduardo Martínez Espinosa (2000). Al recurrir a las fotos de Ekholm para las fases Ocós, Cuadros, Jocotal y Duende encontramos 160 tepalcates con símbolos. También entre los trabajos mencionados encontramos alrededor de 200 fotos de vasijas completas. Sumando a estas fotos los tepalcates y negativos consultados por nosotros en el NWAF obtenemos un total de más de 600 tepalcates con símbolos y alrededor de 200 vasijas completas para el analisis. Entendemos que esto no es todo el material que se ha excavado de Izapa, sin embargo creemos que es suficiente para plantear determinadas valoraciones generales.
Para cumplir con el propósito señalado al inicio del presente artículo, empezaremos por descubrir los diversos símbolos por fases cerámicas y después ensayaremos las interpretaciones correspondientes.

\section{El complejo simbólico en la cerámica de Izapa}

\section{Fase Izapa-Ocós (ca. 1500-1200 a.C.)}

Desafortunadamente la cantidad de cerámica de Ocós conservada en la bodega de la Fundación Arqueológica Nuevo Mundo es bastante escasa: solamente dos fragmentos con diseños reconocibles (Figura 2.a y f). Por ello recurrimos a las fotografías publicadas por Ekholm, como ya lo mencionamos arriba. Entre ellas encontramos 54 casos de tepalcates para la fase Ocós en los cuales se distinguen los siguientes símbolos: 1) Puntos. Al parecer fueron impresos con algún tipo de palo (Ekholm, 1969). Se alinean casi siempre a lo largo del borde (Figura 2.a); 2) Líneas rectas. Se pueden encontrar en dos líneas paralelas que corren por debajo del borde formando una banda horizontal (Figura 2.byd). También se encuentran bandas verticales y diagonales (Figura 2.c). Otra variante de este símbolo lo constituyen líneas diagonales paralelas que bajan desde la banda horizontal (Figura 2.d);3) Reja. Compuesto de líneas diagonales cruzadas, este símbolo generalmente parte desde la banda horizontal (Figura 2.f). Además de los tres símbolos mencionados, cabe mencionar un motivo que es común para la fase Ocós: un estampado ondulante de concha parecido a olas (Figura 2.e) (Lowe, Lee y Martínez E., 2000: 159).

\section{Fase Izapa-Cuadros (ca. 1200-1000 a. C.)}

Para la Fase Cuadros se encontraron en la NWAF 32 tepalcates con símbolos. También tomamos otros 20 tepalcates de las fotos de Ekholm. En total contamos con 52 muestras con los siguientes símbolos: 1) Puntos. Impresos con diferentes tipos de semillas y palos (Ekholm, 1969). Se agrupan ahora en una o varias líneas 
paralelas verticales, horizontales o diagonales (Figura 3.a-f, i, k). En esta fase los puntos son más diversos en comparación con la fase Ocós; 2) Líneas rectas. En la Fase Cuadros el motivo de las bandas sigue apareciendo sin muchos cambios (Figura 3.a-e, i-l), aunque ahora dentro de la bandas verticales y diagonales aparecen líneas paralelas y puntos impresos con semillas (Figura 3.e y j). También a partir de Cuadros es posible destinguir dos tipos de líneas rectas denominadas por nosotros líneas tipo A y líneas tipo B. Las líneas tipo A son delgadas líneas horizontales o diagonales casi siempre paralelas que llenan una parte de la pieza, formando una especie de fondo sobre el cual en ocasiones aparecen varios símbolos (Figura 3.a, f y k). Las líneas tipo B son líneas paralelas, gruesas, claras, bastante separadas unas de otras (Figura 3.g). También aparece el tipo de línea recta interrumpida terminada con una curva (Figura 3.h);3) Rombo. Elúnico ejemplar existente presenta solamente la mitad del símbolo (Figura 3.i), pero creemos que es posible restaurar el resto del rombo de la manera como se muestra en la figura 3.i, tomando como ejemplos los rombos del arte mesoamericano y mundial (Kolpakova, 2008). Este rombo contiene en su interior un punto redondo y grande (Figura 3.i); 4) Líneas onduladas. Sólo en una ocasión aparece este símbolo. Consiste en líneas onduladas paralelas dispuestas en diagonal (Figura 3.j); 5) Medios círculos. Corren separados por debajo del borde (Figura 3.1) o unidos en línea ondulada diagonal (Figura 3.k).

\section{Fase Izapa-Jocotal (ca. 1000-850 a.C.)}

En esta fase en la bodega de NWAF se encontraron 31 tepalcates con símbolos. También tomamos otras 40 muestras de las fotos de Ekholm. En total son 71 tepalcates con los siguientes símbolos: 1) Puntos. En la Fase Jocotal los puntos al perecer ya no se emprimen con semillas sino son incisos con diferentes tipos de palos; sin embargo, los artistas todavía imitan la forma de las semillas creando pequeñas rayas también incisas
(Figura 4.c). En esta fase encontramos diseños donde los puntos se agrupan en línea curva o donde los puntos aparecen dentro de un triángulo redondeado (Figura 4.a y b);2) Líneas rectas, Este símbolo con sus variantes pasó desde Cuadros a Jocotal casi sin cambios. Los diseños de bandas son muy parecidos a los de Cuadros; con frecuencia los encontramos con motivos en su interior (Figura 4.d). También se mantienen los diseños de líneas tipo A у в los cuales no mostraron cambios significativos (Figura 4.a, d, e). El único motivo nuevo que observamos en una pieza de cerámica está compuesto por líneas paralelas diagonales que están divididas por una línea horizontal (Figura 4.e); 3) Reja. Aparece sólo una pequeña parte del símbolo y exclusivamente en una ocasión (Figura 4.g); 4) Medio círculo. Este símbolo está formado por una o dos líneas que casi siempre están acompañadas con puntos (Figuras 4.c y h). Tambien hay un ejemplar de línea diagonal conformada por una serie de medios círculos, motivo que se parece mucho al encontrado en Cuadros (Figura 4.f); 5) Triángulo. Tiene forma oblicua conteniendo en su interior puntos (Figura 4.b);6) Línea escalonada. Aparece por primera vez aunque en ella se percibe sólo un peldaño (Figura 4.i).

\section{Fase Izapa-Duende (ca. 850-650 a.C.)}

Los símbolos de la Fase Duende siguen los mismos rasgos de las fases anteriores practicamente sin cambios. En la bodega de NWAF se encontraron 27 tepalcates. También tomamos otras 23 muestras de las fotos de Ekholm. Para esta fase contamos entonces con 50 tepalcates en total con los siguientes símbolos: 1) Puntos. Sus diseños y formas son iguales de los de las fases anteriores (Figura 5.a). La novedad es que aparecen puntos pintados en negativo correctamente redondos y más grandes (Figura 5. b). Los pequeños puntos-rayas que imitan semillas siguen apareciendo (Figura 5.c);2) Líneas rectas. El motivo de bandas permanece sin muchos cambios (Figura 5.d). El motivo de líneas tipo A disminuyo significativamente dando mayor espacio al 
de líneas tipo B; éstas últimas en su mayoría aparecen en posicion diagonal (Figura 5.d y e). Se siguen observando las líneas paralelas diagonales que están divididas por una línea horizontal (Figura 5.e); 3) Medio círculo. Se conforma de dos o más líneas (Figura 5.f); 4) Línea escalonada. Muy parecida a la de la fase anterior (Figura 5.g); 5) Línea ondulada. Se cuenta con sólo un ejemplar de este símbolo. Lo encontramos pintado en negativo (Figura 5.h).

\section{Fase Izapa-Escalón (ca. 650-450 a. C.)}

Para esta fase localizamos 19 tepalcates con los siguientes símbolos: 1) Puntos. Su cantidad disminuyo significativamente (encontramos sólo 4 tepalcates) pero los que se mantienen son más grandes de diámetro y están mejor elaborados (Figura 6.a y h); 2) Líneas rectas. Las bandas se decoran con líneas horizontales o verticales paralelas (Figura 6.b y g). Las líneas diagonales tipo B siguen sin cambios (Figura 6.c) pero las líneas tipo A a partir de este momento ya no se van a observar; 3) Medio círculo. En esta fase los medios círculos están compuestos de dos o más líneas o se unen en línea ondulada alrededor del cuello de la pieza (Figura 6.a, dy f); 4) Reja. El símbolo es practicamente igual a los de fases anteriores (Figura 6.e); 5) Triángulo. Hay un diseño que presenta un triángulo de cabeza con puntos en su interior como en la fase Jocotal (Figura 6.h); 6) Línea escalonada. Ahora está formada por dos o más líneas (Figura 6.g); 7) Zig-zag. Se observa un diseño con una pequeña parte de zig-zag horizontal debajo del borde de la cerámica (Figura 6.i).

\section{Fase Izapa-Escalón-Frontera (ca. 650-300 a. C.)}

Para Escalón-Frontera la decoración sigue sin cambios significativos respetando la tradición artística de las fases anteriores. Encontramos 30 tepalcates que contenían los símbolos siguientes: 1) Puntos. La cantidad de muestras de este símbolo sigue disminuyendo (encontramos sólo 5 tepalcates). Los puntos que se conservaron se agrupan formando un diseño de fondo o dentro de triángulos como en las fases anteriores (Figura 7.a, b y h); 2) Líneas rectas. Son diagonales y paralelas y salen de la banda horizontal como en fases anteriores (Figura 7.c) pero ahora se llegan a encontrar colocadas unas contra otras de tal manera que forman un triángulo en el vértice (este diseño se localiza a su vez dentro de una banda) (Figura 7.d);3) Medios círculos. Crece el número de piezas de cerámica que contienen este símbolo (encontramos 8 tepalcates). La mayoría de las veces son medios círculos dobles dispuestos hacia arriba (Figura 7.b y f). Se observa también el mismo diseño de medios círculos unidos en línea horizontal como el encontrado en la fase Escalón (Figura 7.g); 4) Triángulo. Lo encontramos de cabeza con puntos en su interior como en las fases anteriores (Figura 7.h);5) Línea escalonada. Siguen apareciendo las líneas paralelas que forman un escalón (Figura 7.e).

\section{Fase Izapa-Guillén (ca. 300-50 a. C.)}

Hallamos 38 tepalcates con símbolos para esta fase de apogeo en Izapa, entre los cuales tenemos: 1) Puntos. La cantidad de casos aumentó (16 tepalcates) (Figura 8.a-d $\mathrm{y}$ h). Aparece un nuevo tipo caracterizado por puntos protuberantes que se destacan sobre la superficie de la cerámica, son más grandes que las demás variantes de este símbolo (Figura 8.ayd). Por primera vez se encuentran puntos perforados (agujeros) que corren alrededor del cuello de la cerámica (Figura 8.b);2) Líneas rectas. Las bandas siguen su desarrollo dentro del patrón establecido anteriormente (Figura 8.a). La novedad radica en que ahora debajo del borde de la cerámica se pueden encontrar anchas acanaladuras o líneas incisas paralelas horizontales en lugar de la tradicional banda (Figura 8.f ye). Cabe señalar que encontramos muy pocos ejemplos de líneas diagonales paralelas (Figura 8.c);3) Mediocírculo. El símbolo permanece aquí sin cambios significativos, solamente aumentó la cantidad de líneas con las que se conforman (Figura 8.g); 4) Triángulos. Mientras que 
en un diseño los triángulos aparecen pintados de rojo (Figura 8.h), en otro el triángulo presenta puntos en su interior (Figura 8.d); 5) Línea ondulada. Se encontró una pieza de cerámica con dos líneas paralelas de este tipo (Figura 8.e); 6) Línea escalonada. Sigue apareciendo compuesta por varias líneas (Figura 8.i).

\section{Fase Izapa-Hato (ca. 50 a. C.-100 d. C.)}

En esta fase no se encontraron piezas decoradas locales. La escasez de material en esta fase se debe a la posible interrupción del crecimiento de Izapa hacia el primer siglo de nuestra era, lo cual ocasionó que la mayoría de la cerámica de las ofrendas de Izapa fuera importada (Lowe, Lee y Martínez E., 2000: 179).

La única pieza de cerámica local encontrada es una olla (Figura 9) que contiene los siguientes símbolos: 1) Líneas rectas. Observamos una banda vertical así como líneas verticales y horizontales que forman un diseño escalonado (Figura 9); 2) Triángulos. Dispuestos de cabeza y en posición normal con una reja en su interior (Figura 9). Cabe señalar que esta combinación de dos símbolos (triángulo y reja) aparece por primera vez; 3) Reja. Como acabamos de mencionar, ahora aparece dentro de los triángulos (Figura 9); 4) Línea escalonada. Formada por varias líneas que ocupan gran parte del diseño de la vasija. Esta línea escalonada destaca por su gran tamaño (Figura 9).

\section{Fase Izapa-Itstapa (ca. 100-250 d. C)}

En la Fase Itstapa observamos muy poca cantidad de piezas con motivos geométricos (8 en total), de los cuales destacamos los siguientes: 1) Puntos. No hay muchos ejemplares de este elemento; los únicos que encontramos muestran puntos agrupados en línea alrededor de la vasija (Figura 10.a);2) Líneas rectas. Siguen apareciendo las líneas opuestas paralelas y diagonales que bajan de la banda (Figura 10.d). Dentro de ese motivo hay una variación consistente en líneas oblicuas (Figura 10.b);3)
Medios círculos. Están conformados por varias líneas y se muestran unidos en una serie horizontal (Figura 10.c); 4) Triángulo. Los pequeños triángulos están seriados en una línea que corre alrededor de una greca (Figura 10.e); 5) Greca escalonada. Por primera vez aparece este símbolo en la cerámica de Izapa; los escalones se muestran en forma de pequeños triángulos. El símbolo decora una especie de oreja (Figura 10.e).

\section{Fase Izapa-Jaritas (ca. 250-400 d.C.)}

Encontramos 40 tepalcates con los siguientes símbolos: 1) Puntos. Se utilizan como parte de diseños complejos y son de variadas formas: parecidos a rayas, con forma de semilla, totalmente redondos, protuberantes, etcétera (Figura 1l.a, b, f, j); 2) Líneas rectas. En esta fase este símbolo es más numeroso y diverso, pues llega a formar diseños complejos (Figura ll.a y b). Es notable mencionar que vuelven a aparecer las líneas paralelas verticales o diagonales que parten de la banda tal como ya lo habíamos observado en las primeras fases (Figura ll.e). Las bandas aparecen conteniendo en su interior puntos y líneas paralelas verticales (Figura ll.a y c); 3) Medio círculo. No presenta cambios este símbolo. Es de varios tamaños. Los medios círculos están compuestos por dos o varias líneas, a veces están unidos en serie (Figura ll.g); 4) Triángulo. El símbolo no presenta cambios significativos aumentando únicamente la variedad de sus tipos (Figura ll.d, f, h, i yl). Se observa un nuevo tipo formado por varias líneas paralelas diagonales contenidos dentro de la banda horizontal y que presentan dentro de sí un punto (Figuras ll.d y f); 5) Espiral. Este símbolo ya está presente en la fase anterior pero en cerámica importada. En la fase Jaritas la espiral se destaca como elemento independiente y ya es bastante numeroso (Figura 1l.h). Como variante de este símbolo encontramos un gancho oblicuo (Figura 11.1); 6) Rombo. El único ejemplo que encontramos está formado por varias líneas paralelas con un punto adentro (Figura 11.j); 7) Línea ondulada. Aparece en posicion vertical conformada por medios 
círculos (Figura ll.m); 8) Líneas curvas. Se encuentran partiendo desde una banda (Figura ll.n); 9) Greca. Sólo hay un ejemplar de este símbolo (Figura ll.k).

\section{Fase Izapa-Kato (ca. 400-500 d.C.)}

Hallamos 16 tepalcates con diversos símbolos entre los cuales destacamos los siguientes: 1) Puntos. Aparecen rara vez, y cuando aparecen lo hacen como protuberancias de gran tamaño (Figura 12.a); 2) Líneas rectas. Líneas paralelas y diagonales que son muy parecidas a las de las primeros fases (Figura 12.b, c y f). Las bandas siguen apareciendo sin cambios (Figura 12.c, d y f); 3) Medios círculos. Conformados por varias líneas (Figura 12.d); 4) Triángulos. Incluyen líneas paralelas y diagonales en su interior (Figura 12.c); 5) Espiral. Se encontró sólo un ejemplo sin cambios notables (Figura 12.c); 6) Líneas onduladas. Son semejantes a las encontradas en fase anterior. Se encuentran en un par dispuesto en posicion vertical y dividido por una línea también vertical (Figura 12.d); 7) Línea curva. De esta línea curva brotan hacia arriba líneas paralelas rectas (Figura 12.c). Una composición parecida vemos en otro caso con la excepción de que la línea curva tiene forma de escalón y las líneas paralelas, que son oblicuas, brotan hacia arriba y hacia abajo (Figura 12. f). Otro tipo de línea curva, que baja del borde, tiene forma de letra "S" (Figura 12.e).

\section{Fase Izapa-Loros (ca. 500-600 d.C.)}

Para esta fase fue poca la cantidad hallada de piezas decoradas con símbolos. Son 8 en total. La mayoría de los símbolos se concentran en una vasija de pasta café (Figura 13. dy e). Los símbolos son: 1) Puntos. Se encontró sólo una pieza con puntos grandes que corren en línea horizontal por debajo del borde (Figura 13.a); 2) Líneas rectas. Son paralelas verticales y diagonales similares a las de las primeras fases (Figura 13.b y c). También encontramos líneas que forman varios tipos de bandas (Figura 13.b-e); 3) Medios círculos. Formados por varias líneas, brotan de bandas ubicadas en las cuatro direcciones (Figura 13.e); 4) Greca. Destaca por su gran tamaño (Figura 13.d); 5) Línea curva. Este símbolo se dispone sucesivamente formando especies de "olas". También adopta la forma de media letra "S" (Figura 13.d).

\section{Fase Izapa-Metapa (ca. 600-700 d.C.)}

Encontramos 10 tepalcates con diversos símbolos entre los cuales destacamos los siguientes: 1) Puntos. Sus rasgos son muy similares a los de las primeras fases (Figura 14.a), incluso hay una pieza de cerámica con puntos sobre líneas parecidos a las impresiones de semillas de la fase Cuadros (Figuras 3.a y e; 14.b); 2) Líneas rectas. Se observan líneas paralelas tanto verticales como horizontales y opuestas semejantes a las de las fases anteriores (Figura 14.b y c). También hay bandas que por lo regular poseen diseños en su interior (Figura 14.c y e); 3) Medio círculo. Se encontró una pieza con este símbolo aunque incompleto pero parecido a los de fases anteriores (Figura 14.b); 4) Reja. Está dentro de una banda (Figura 14.e); 5) Rombo. El único ejemplo tiene la forma de un meandro (Figura 14.f); 6) Línea escalonada. Se encontró un sólo ejemplar trazado con una línea un tanto oblicua (Figura 14.e); 7) Línea ondulada. Se encontró sólo un ejemplo de este símbolo conformado por líneas onduladas paralelas horizontales (Figura 14.d).

\section{La Fase Izapa-Peistal (ca. 700-900 d.C.)}

Hallamos 74 tepalcates con diversos símbolos entre los que se destacan estos: 1) Puntos. Encontramos diversos tipos: protuberantes, impresos, con forma de rayas, y perforados (Figura 15.a-e y n). Hay un ejemplo donde vemos puntos sobre líneas tal como en la fase Metapa (Figuras 14.b; 15.e); 2) Líneas rectas. Destaca la gran cantidad y variedad de este símbolo. Vemos varios ejemplos de aquella variante que muestra tres líneas paralelas y diagonales (Figura 15.f). Las bandas mantienen su aparición con su diversidad (Figura 15.a, g, 
h, i, j, l, m y n); 3) Medio círculo. De este símbolo existen tanto ejemplos semejantes a los de las fases anteriores (Figura 15.g), como nuevas variaciones más complicadas. Entre estas últimas se destaca una composición de pequeños medios círculos unidos de tal manera que parecen representar olas (Figura 15.m). También hay que mencionar un medio círculo compuesto por dos líneas paralelas que tienen un punto adentro (Figura 15.n); 4) Triángulos. Tenemos un tipo de triángulo semejante al encontrado en una fase anterior: de cabeza cayendo del borde de la cerámica y con líneas paralelas en su interior (Figura 15.k); 5) Reja. La posición y tamaño del símbolo son variables aunque siguen el patrón establecido anteriormente (Figura 15.h y i); 6) Línea curva. Hay algunas que tienen apariencia de letra "S" como las encontramos en la fase Kato (Figura 15.1). También hay una variante de tipo "gancho" dentro de la cual hay puntos (Figura 15.n); 7) Zig-zag. Este símbolo cambio de forma ya que ahora es una línea en forma de pequeños escalones que están en diagonal (Figura 15.j).

\section{Fase Izapa-Remanso (ca. 900-1200 d.C.)}

En esta última fase de la secuencia cerámica se observan muchos diseños muy complejos al igual que en la fase anterior. Sin embargo, a la par se encuentran otros bastante simples semejantes a los de las primeras fases. Encontramos 50 tepalcates con diversos símbolos entre los cuales podemos destacar los siguientes: 1) Puntos. Aquí observamos todo tipo de puntos: impresos, perforados, con forma de rayas, y modelados (Figura 16.a-c, f y h); 2) Líneas rectas. Vemos bandas formadas por dos o más líneas (Figura 16.d, i y l). Destaca la gran cantidad de líneas diagonales y verticales paralelas de los tipos encontrados en fases anteriores (Figura 16.d); 3) Triángulo. Encontramos los mismos tipos de triángulos que detectamos en fases anteriores: decorados en su interior con líneas paralelas diagonales (Figura 16.g). También contamos con otro triángulo formado por tres triángulos uno dentro de otro (Figura 16.i); 4) Medio círculo. Este símbolo no presenta cambios significativos (Figura 16.f); 5) Reja. El único ejemplo que encontramos tiene la reja modelada de gran tamaño y adentro de cada rombo formado por la reja hay un punto (Figura 16.h); 6) Espiral. La mayoría de las veces encontramos la espiral como parte de una composicón mayor (Figura 16.k);7) Línea ondulada. Este símbolo no presenta cambios significativos y se ubica en posición horizontal (Figura 16.j); 8) Greca escalonada. Aquí observamos este símbolo en forma de un gancho con escalera contenido a su vez dentro de un diseño complejo (Figura 16.1); 9) Zig-zag. El único ejemplo de ese símbolo tiene forma un tanto oblicua (Figura 16.m).

\section{Interpretación de los símbolos}

Hemos descrito un total de 12 símbolos contenidos en la cerámica de Izapa en sus distintas fases. Estos son: puntos, líneas rectas, línea ondulada, zig-zag, línea curva, medio círculo, reja, rombo, triángulo, greca escalonada, espiral y línea escalonada. Ahora pasaremos al análisis del significado de cada símbolo por separado.

\section{Puntos}

Según Ariel Golan y Boris Ribakov, los puntos en la cerámica por lo regular representaban semillas (Golan, 1994: 86; Ribakov, 1981: 178). En el caso concreto de Izapa podemos ver que en la Fase Cuadros algunos puntos eran impresos justamente con semillas (Figuras 3.a ye). Esto elocuentemente indica que ése era el significado de este símbolo también en la cerámica prehispánica.

Analizemos ahora una variante que es característica para la cerámica de Izapa: los puntos ubicados dentro de un triángulo (o medio círculo triangular) (Figuras 4.b, 6.h, 7.h, 8.d). De acuerdo con Golan, los triángulos y medios círculos simbolizan nubes (Golan, 1994: 15-16). Las combinaciones de puntos-semillas con los símbolos de las nubes expresan por su parte la súplica del hombre por el contacto entre la lluvia y las siembras (Golan, 1994: 
16). Si consideramos la creencia donde "a menudo el agua que cae desde el cielo y hace la tierra fertil se comparaba con el torrente de esperma del dios de cielo que la envía para la madre tierra" (Biedermann, 1996: 73), y otra registrada por Girard acerca de que "el agua celeste [...] es la materiafertilizante que desde lo alto del cielo cae sobre la tierra [...] como cae el grano tirado por el agricultor" (Girard, 1949: 844), entonces podremos sugerir que en ciertos contextos los puntos no sólo representan semillas sino, por extensión, también gotas de lluvia y semen divino. En ese ejemplo podemos ver el proceso de traspaso y al mismo tiempo superposición de significados en un sólo símbolo cuando "un símbolo es capaz de expresar simultáneamente diversos significados" (Nájera en Del Moral, 2000: 84). En Izapa esta propuesta se confirma con una composición de la fase Remanso (Figura 16. f) en la que vemos que los puntos tienen forma de gotas saliendo de medios círculos-nubes. En otro caso, perteneciente a la fase Metapa (Figura 14.b), los puntos en forma de semilla están colocados en las líneas paralelas verticales que representarían la lluvia que a su vez desciende del medio círculo-nube. El mismo concepto de puntas-gotas observamos en la escultura monumental olmeca, donde la lluvia fertilizante esta representada por el motivo "punto colgante" (Figura 17) (Magni, 2008: 254). Entonces, siguiendo las interpretaciones de Golan, Biedermann, Girard y Magni, en la cerámica de Izapa los puntos no son otra cosa que gotas de lluvia y semen divino.

Veamos ahora un tipo de puntos muy especial. Se trata de puntos perforados (agujeros) que, como vimos, se encuentran en la cerámica de Izapa a partir de la fase Guillén (Figuras 8.b, 15.d y 16.b). Pensamos que las vasijas con este tipo de puntos posiblemente estaban relacionadas con el culto agrario, en especial con los ritos de petición de lluvia a través de magia imitativa. Entre los mayas actuales existen casos en los cuales la jícara es el instrumento de los dioses de la lluvia, pues de ella estas divinidades vierten las aguas celestes sobre la tierra (Girard, 1949: 830, 1090). La misma creencia podemos observar en la estela l de Izapa donde la vasija es el contenedor para las nubes con lluvia (Moral del, 2000: 83) (Figura 19). Sugerimos, siguiendo a Ribakóv (1981: 181), que las vasijas con puntos perforados representaban la idea de atrapar la lluvia o el agua celeste a través de la manipulación del agua terrestre. En el caso de la cerámica de Izapa pensamos que la vasija era el contenedor con las aguas celestes y los puntos eran agujeros en el cielo de los cuales brotaba la lluvia.

\section{Líneas rectas}

Las líneas que forman una banda horizontal representan el cielo (Golan, 1994: 14). Otro tipo de líneas rectas son las líneas paralelas diagonales o verticales múltiples que salen de la banda horizontal, éstas representan la lluvia (Ribakov, 1981: 168; Golan, 1994: 14; Biedermann, 1996:73). En la cerámica de Izapa se encuentran muchos ejemplos de este uso del símbolo, desde la primera fase hasta la última (Figura 25). Por ejemplo, en la Fase Ocós y Jaritas (Figura 2.d y ll.e) vemos dos composiones similares en las cuales notamos cómo de la banda horizontal salen las líneas diagonales paralelas. Estas composiones pueden interpretarse de la misma manera: las líneas paralelas que parten de la banda (cielo) son la lluvia que asegura el crecimiento de maíz (Girard, 1949: 188). A veces las líneas paralelas se encuentran dentro de la banda horizontal (Figuras 3.e, 6.b, 11.c, 13.c), lo cual puede representar al cielo cargado de agua. Ese mismo concepto observamos en el arte olmeca, donde líneas verticales paralelas representan la lluvia que sale de la nube (Figura 17). En este ejemplo vemos otro proceso muy peculiar cuando para el mismo fenómeno de la naturaleza (en este caso la lluvia) se utilizan dentro de la misma imagen dos motivos diferentes: puntos colgantes (que como vimos es el semen divino representado por las gotas de agua) y líneas rectas paralelas y verticales (que son la lluvia). También podemos verlo en la estela 21 de Izapa donde la lluvia en forma de líneas paralelas verticales gruesas sale de las espirales-volutas que son nubes (Figura 18). Podemos concluir que todos estos 
símbolos expresaban la súplica por la lluvia fertilizante por medio de la imitación, como lo vimos líneas arriba. Por último mencionaremos que ciertas bandas verticales también podían servír para dividir los espacios de la vasija (Figura 9).

\section{Lineas onduladas}

Las líneas onduladas verticales u horizontales tenían dos significados: agua y lluvia (Golan, 1994: 14). La línea ondulada apareció como representación esquemática del río y luego adoptó el significado de agua en general (Golan, 1994: 75). La línea ondulada y el zig-zag, en opinión de Golan, es el mismo símbolo pero elaborado de diferente manera. Ambos trazos representaban al río, al agua, a la lluvia o a la serpiente que simbolizaba a las aguas terrestres (Golan, 1994: 82) (Figura 26). A la misma conclusión llega Girard cuando señala la equivalencia que desde tiempos antiguos han tenido las figuras angulares y las circulares (Girard, 1949: 1082, 1086). En la cerámica de Izapa el proceso de equivalencia se puede observar en un ejemplo proveniente de la fase Remanso (Figura 16.m) en el cual el zig-zag tiene forma oblíua cercana a la forma de la línea ondulada. Vemos entonces que el símbolo de las líneas onduladas es bastante persistente sobre todo si lo juntamos con el zig-zag (Figura 25). Los habitantes de Izapa tambien atribuían el significado de lluvia o agua a las líneas onduladas cuyos ejemplos encontamos en varias estelas (Figuras 19-21). Por eso creemos que en la cerámica de Izapa su significado también era agua, lluvia o serpiente terrestre.

\section{Zig-zag}

Como vimos, las líneas en zig-zag representaban la lluvia, el agua, el río o la serpiente por su parentezco con la línea ondulada (Golan, 1994: 82). Girard considera que el zig-zag también es símbolo de la serpiente relámpago, es decir, de la serpiente celeste (Girard, 1949: 1066). La evidencia de que el zig-zag pudo significar relámpago la tenemos en una composición de la Fase Peistal (Figura 15.j) en la cual dos zig-zags, con forma muy parecida a la de un relámpago, aparecen justamente dentro de la banda celeste con líneas paralelas (cielo con lluvia). Podemos por ello suponer, que en Izapa el zig-zag al inicio significaba agua o lluvia pero después asimiló, por la similitud en su forma, el significado de relámpago.

\section{Líneas curvas}

Creemos que las líneas curvas como las onduladas están también relacionadas con el agua. La evidencia más clara de esto la tenemos en una cerámica de la Fase Kato (Figura 12.f) en la cual vemos cómo de la línea curva, ubicada justamente dentro de la banda-cielo, parten las líneas paralelas que representan la lluvia. Podemos de esta manera sugerir que las líneas de este tipo son torrentes de agua celeste.

Además, pensamos que en las líneas curvas se puede apreciar el mismo proceso de equivalencia entre las figuras circulares y las angulares (Figura 26). En la tabla comparativa observamos la similitud de la línea escalonada de un sólo peldaño con la línea curva, por ejemplo. Esta equivalencia, creemos, se da también a nivel de los significados de tal manera que ambos símbolos, línea curva y línea escalonada de un peldaño, representaban el agua celeste que baja a la tierra. Esta idea está representada a partir de la fase Jocotal a través de la línea escalonada de un peldaño y a partir de la fase Jaritas por medio de las líneas curvas (Figura 25).

En lo que concierne al símbolo de la letra "S", Grieder opina que éste y la greca parecen ser formas alternas de un mismo símbolo (Grieder, 1987: 110). Golan piensa que la "S" era una serpiente vinculada con el cielo (Golan, 1981: 72). Pye y Gutiérrez proponen que en la iconografía olmeca ese símbolo representaba al glifo de la nube que probablemente significaba la tormenta con los vientos violentos (Pye y Gutiérrez, 2007: 239). Magni señala que la "S" es el símbolo del vapor-humo (Magni, 2008: 256). 
Considerando el ejemplo del arte olmeca donde del símbolo "S" salen líneas paralelas verticales (que son lluvia) más otro ejemplo donde del mismo símbolo salen "puntos colgantes" (que son gotas del agua representando a la lluvia fertilizadora) (Figuras 22 y 23), entonces suponemos que el símbolo "S" en la cerámica de Izapa era celeste y se refería al vapor o nube.

\section{Medios círculos}

Como vimos, los medios círculos representaban a las nubes debido a la semejanza en sus formas (Golan, 1994: 15). Además, los puntos adentro o alrededor de un medio círculo, así como los puntos dentro de los triángulos, simbolizaban lluvia, como lo discutimos líneas arriba. Esto lo respaldan los motivos encontrados en la cerámica de Izapa. En vasijas de las fases Escalón y Escalón-Frontera, por ejemplo (Figura 6.a y 7.b), hallamos dos motivos similares de medios círculos rodeados por puntos, los cuales no son otra cosa que gotas-semillas saliendo de la nube. En ocasiones la posición de la composición al parecer era invertida (en tal orden, la banda por debajo del borde de la vasija pasaba a representar a la tierra, mientras que la parte inferior de la vasija quedaba simbolizando al cielo), lo que explica que el medio cículo apareciera puesto hacia arriba y no hacia abajo. Esto se observa en los ejemplos anteriores y en el caso de la fase Jocotal (Figura 4.c) donde las gotas-semillas están cayendo sobre la tierra desde la nube-medio círculo.

\section{Reja}

El símbolo de la reja antes de la aparición de la agricultura representaba simplemente una red pero con la aparición de la agricultura empezo a simbolizar a la tierra (Golan, 1994: 88). Las líneas cruzadas formadas en reja representan la milpa. Cuando la reja se encuentra dentro de un cuadrado o rombo esto simboliza el parcelamiento de la tierra y del mundo (Girard, 1949: 637,
879). Cabe destacar que en las piezas de cerámica de Izapa también encontramos la reja dentro de las bandas celestes (Figuras 14.e, 15.h y i) y dentro de los triángulos (Figura 9). Por ello aunque estamos de acuerdo con las citas mencionadas arriba acerca de que la reja simbolizaba la tierra parcelada o la milpa, creemos que en ciertos contextos la reja funcionaba como representación de la lluvia. En la Figura 14.e las líneas paralelas (lluvia) simplemente se cruzaron formando justamente una reja. Además, esta reja está debajo de la línea escalonada (torrente) que a su vez se localiza dentro de la banda horizontal (cielo). La reja en este caso, efectivemente, representa a la lluvia.

\section{Rombo}

El significado de este símbolo ha sido abordado ampliamente por nosotros en un artículo anterior (Kolpakova, 2008). Aquí sólo mencionaremos que el rombo simboliza la tierra cultivable, por la semejanza que presentan los rombos con la forma de las parcelas de cultivo (Golan, 1994: 86). Por extensión, el símbolo adoptó también el sentido de la fertilidad agrícola y también de la fertilidad en general, no sólo de la tierra, sino también de lo humano (Golan, 1994: 86 y Ribakov, 1981: 42). Es muy posible que éste sea el significado "básico" de todos los rombos mesoamericanos en sus diferentes contextos (en la arquitectura, los bordados, la cerámica y otras obras). Con el significado de tierra coinciden varios mesoamericanistas como Terrence Grieder (1987: 97-98), Martínez del Sobral (2000: 241), Mary Miller y Karl Taube (2004: 83-84), Zoltán Paulini (2007:334) y Rafaél Girard (1949). Este último además propone la equivalencia de rombo con el cuadrado en su significado de símbolo de la milpa. Girard también especifica que el rombo representa la milpa en la montaña mientras que el cuadrado la milpa en las planicies (Girard, 1949: 636). En la cerámica de Izapa este símbolo no es numeroso, sólo tres casos hallamos. En dos de éstos, los rombos están formados por varios rombos uno dentro del otro; en otros dos casos 
los rombos contienen puntos en el centro (Figura 25). Pensamos que varios rombos colocados uno dentro de otro representan los niveles del Inframundo, el cual, según las creencias mesoamericanas, estaba compuesto de diferentes pisos (Miller and Taube, 2004: 177). En este sentido, el punto en el centro del conjunto de rombos podría ser entendido como el centro de la Tierra. Los rombos y sus puntos en la cerámica de Izapa representan, por tanto, a la Tierra y a su centro.

\section{Triángulos}

De acuerdo con Golan este símbolo tiene dos significados: 1) nubes, 2) Montañas (Golan, 1994). Biedermann además, proporciona dos significados: 1 ) agua (la punta del triángulo hacia abajo), 2) fuego (la punta del triangulo hacia arriba) (Biedermann, 1996: 270). De acuerdo con Golan los medios círculos que simbolizaban a las nubes se transformaron en triángulos (Golan, 1994: 16). En Izapa esta interpretación puede confirmarse por la presencia de puntos (gotas) dentro de los triángulos (Figuras 6.h, 7.h, 8.d) y, a partir de la fase Kato, por líneas paralelas y diagonales (lluvia) dentro de triángulos también (Figuras 12.c, 15.k, 16.g). El significado de estos triángulos se centraba en la súplica por la lluvia como ya lo mencionamos antes. Hay otro ejemplo de triángulo con reja donde la reja igualmente podría representar la lluvia como lo vimos en la Figura 14.e. Pensamos por todo lo anterior que en la cerámica de Izapa los triángulos representaban nubes.

Una variente de este símbolo lo tenemos en el caso de la Figura 10.e, en el cual los triángulos tienen forma de un zig-zag que a su vez forma parte de una greca escalonada (aquí el zig-zag de triángulos actúa en calidad de escalones). Según Girad, en ocasiones los peldaños de las grecas escalonadas se tranformaban en zig-zag y esos zig-zags representaban a las sierpes de nube (Girard, 1949: 1090 y 1091). Aguilera del mismo modo iguala la escalera con el zig-zag (Aguilera, 2007: 244). Como anteriormente supusimos que en Izapa el zig-zag significaba agua, lluvia o relámpago, también es probable que, ese motivo en particular, debía estar relacionado con el agua.

Otro detalle que hay que indicar sobre el triángulo es su segundo significado que señala Golan: montaña. Los encontramos en las estelas de Izapa, donde los triángulos unidos en zig-zag se encuentran en las bandas terrestres (Figuras 20 y 24). Sobre estos triángulos, que a veces contienen símbolos, hubieron varias propuestas de interpretación pero hasta ahora no hay una idea sólida (Quirarte, 2007: 265). Nosotros creemos que por su posición en las bandas terrestres podían representar montañas.

\section{Greca y Greca Escalonada}

El origen geográfico de estos símbolos está íntimamente vinculado con Mesoamérica. Según Girard, estos símbolos aparecen como ulterior desarrollo de la onda (Girard, 1949: 1085). Como mencionamos arriba, Grieder opina que la greca y el signo de la letra "S" parecen ser formas alternas de un mismo símbolo (Grieder, 1987: 110). Si esto es así entonces nuevamente estamos ante el proceso de equivalencia de figuras angulares y circulares, fenómeno también reconocido por Grieder. Aguilera por su parte iguala la greca con la espiral (Aguilera, 2007). La Greca según Grieder es símbolo de la Tierra (Grieder, 1987: 122). Girard considera que la greca escalonada connota varias ideas: serpiente, tierra y lluvia (Girard, 1949: 1086, 1093). Aguilera menciona varios significados vinculados con este símbolo: agua, Quetzalcoatl, viento, serpiente, montañas, cruz, caracoles, y centro de la madre Tierra (Aguilera, 2007: 242). Otra interpretación que proporciona Johansson es la representación de la greca como fuego terrenal (Historia Tolteca-Chichimeca, f. 16v) (Johansson, 2007: 81). Debemos resaltar que casi todas las interpretaciones expuestas relacionan de mayor o menor grado a la greca con la tierra.

En el complejo cerámico de Izapa hay dos grecas escalonadas representadas de diferente manera. Tam- 
bién hay varias grecas simples, una de las cuales (fase Jaritas) tiene forma de gancho cuadrangular parecido al gancho oblicuo de la fase Peistal. Podemos afirmar que tanto el gancho cuadrangular y oblicuo como la greca y la espiral son los mismos símbolos elaborados de diferente manera (Figura 26). Dicha similitud entre estos tres símbolos resulta evidente al observar la tabla comparativa (Figura 25). En realidad es difícil determinar tanto el significado primario de la greca como el significado exacto de ese símbolo en la cerámica de Izapa, pero, tomando en cuenta las interpretaciones generales mencionadas arriba, pensamos que era un símbolo relacionado con la tierra.

\section{Espiral}

A pesar de que la espiral, en la antigua simbólica, por lo regular representaba a las serpientes, se llegan a encontrar contextos donde el significado variaba (Golan, 1994: 19). De acuerdo con Grieder, la espiral en el principio significaba "vulva de la Tierra" y "surgimiento desde la Tierra”, pero después adquirió significados celestes, por ejemplo, "viento" (Grieder, 1987: 105). Una interpretación cercana a Grieder nos da Martínez del Sobral, quien piensa que la espiral era un símbolo del crecimiento en movimiento (Martínez del Sobral, 2000: 236). Aguilera piensa que la espiral representa el modo con el que se creó el mundo-movimiento circular-espirodeo. La misma autora, también iguala la espiral con la escalera, puesto que en las dos subyace la misma idea de poder ascender o descender (Aguilera, 2007: 244). Thompson relaciona la espiral con la serpiente (Thompson, 1997: 308). Johansson interpreta a la espiral como símbolo del agua (Historia Tolteca-Chichimeca, f. 16v) (Johansson, 2007: 81).

Para acercarnos más al significado de dicho símbolo en la cerámica de Izapa hay que dirigirnos a las estelas de Izapa. Analicemos la Estela 1 donde vemos imágenes de espirales (volutas) que rodean a un recipiente (vasija) cargado por el dios de la lluvia, espirales que representan a las nubes o al agua (Figura 19) (Moral del, 2000: 83). En la estelas 21 y 26 observamos también la línea de espirales-nubes de las cuales sale la lluvia en forma de líneas rectas u onduladas (figuras 18 y 20). Otros ejemplos de espirales-agua formadas en líneas, los podemos ver en las estelas 5 y 67 (Figuras 21 y 24). Anteriormente vimos que el significado del símbolo "S" que proponen Pye y Gutiérrez es el de la nube que probablemente representaba la tormenta con los vientos violentos (Pye y Gutiérrez, 2007: 239). Si consideramos que la "S" está formada por dos espirales unidas, como se puede observar en algunas estelas donde las espirales se unen en una línea para representar al agua (Figuras 21 y 24) (Moral del, 2000: 84), entonces tanto el símbolo de la "S" como la espiral representan nubes cargadas con agua tanto en las estelas de Izapa como en la iconografía olmeca. Tomando en cuenta todos los significados citados líneas arriba y su representación en las estelas de Izapa, podemos entonces sugerir que el significado de la espiral en la cerámica de Izapa estaba relacionado con el agua, en particular con las nubes.

\section{Línea escalonada}

El significado de la línea escalonada ya ha sido abordada líneas arriba: representaba agua celeste o lluvia. Golan considera que la línea escalonada y el zig-zag son el mismo símbolo de la lluvia o el agua, pero ejecutados de distinta forma (Golan, 1994: 16). Girard piensa que las líneas escalonadas son nubes en forma de escaleras o en forma de la serpiente de nube que sirve de escalera divina para el tránsito de los dioses (Girard, 1949: 825,1091). En la cerámica de Izapa se encuentra un ejemplo interesante de zig-zag elaborado en diagonal que adopta la forma de escalones (Figura 15j). Este ejemplo se puede considerar como un caso claro donde el zig-zag se transforma en escalones. Este motivo ha sido definido, anteriormente, en su contexto, como representación de un relámpago. En lo que concierne a la línea escalonada con un peldaño, hemos expresado que se trata de un torrente de agua 
celeste, interpretación que podemos confirmar con aquél ejemplo donde el escalón está formado por tres líneas paralelas que se parecen mucho a las líneas que representan la lluvia o el agua (Figuras 8.i, 9).

\section{Conclusiones}

Como resultado de esta investigación se han encontrado los siguentes símbolos en la alfarería de Izapa: puntos, líneas rectas, líneas onduladas, rombos, rejas, medios círculos, triángulos, líneas escalonadas, grecas, espirales, líneas curvas, zig-zag. Todos estos símbolos están incluídos en una tabla general comparativa que se anexa al presente trabajo (Figura 25).

En esta tabla comparativa general, mostramos el conjunto de los principales símbolos que aparecen en las primeras fases al igual que el desarrollo de ellos de una fase a otra. Los símbolos que aparecen primero son: puntos, conjuntos de líneas rectas, reja, medio círculo, rombo, línea ondulada, triángulo, línea escalonada y zig-zag. ${ }^{4}$ Los demás tres símbolos - la greca, la espiral y línea curva - aparecen bastante tarde a partir de la Fase Itstapa (100-250 d.C.). Ahí podemos percibir cómo algunos de los símbolos van haciéndose más complejos tanto en técnica como en el propio diseño del símbolo, pero su representación grafica inicial no se cambia.

Brevemente mencionaremos los significados primigenios propuestos para cada símbolo: puntos — semillas y gotas-; líneas rectas — lluvia —; línea ondulada — agua o serpiente-; rombo - tierra o milpa—; reja - milpa o tierra cultivada-; medio círculo - nube-; triángulo - nube-; linea escalonada - agua celeste, torrente, serpiente, lluvia o nubes-; greca - al parecer inicialmente crecimiento y creación en movimiento, luego símbolo relacionado con la tierra-; espiral -inicialmente crecimiento y creación en movimiento, luego símbolo relacionado con el agua -; línea curva - agua celeste, torrente—;zig-zag —agua, lluvia, serpiente o relámpago—. Para una mejor visualización todos estos significados se han incluído en la Figura 27.
Después de analizar cada símbolo en la cerámica de Izapa podemos dividirlos en dos grandes grupos: símbolos de tierra (rombo, reja, puntos, greca) y símbolos de agua (puntos, líneas rectas, líneas onduladas, líneas escalonadas, medios círculos, triángulos, espirales, zigzag). Los símbolos más persistentes que sólo muestran algunos cambios durante toda la secuencia cerámica de Izapa son: 1) Puntos, sólo cambian de tamaño y forma; también cambia la técnica de su elaboración; 2) El motivo de bandas horizontales y verticales, prácticamente no tiene cambios; 3) El motivo de líneas diagonales y verticales paralelas que bajan de la banda horizontal permanece sin transformaciones, aunque en algunas fases desaparece; 4) El triángulo, que aparece en varios tipos y tamaños en posición hacia arriba y hacia abajo, únicamente cambia en el modo de representar al agua que contiene dentro: al principio son puntos y luego son líneas paralelas diagonales; 5) Medio círculo, no tiene muchos cambios durante la secuencia cerámica; 6) Reja, no se encuentra en algunas fases intermedias, pero sin duda es un símbolo común en la cerámica de Izapa que logró persistir sin cambios significativos. Como vemos, todos los símbolos que son más constantes coinciden con los símbolos que aparecen primero en la secuencia, hecho que sugiere que los símbolos al igual que algunos componentes de la religión parecen mantenerse inalterables al paso de los milenios (López Austin, 2002: 17). Así que es muy probable que sus significados primigenios permanecieran durante toda la secuencia de las fases analizadas, sin embargo no descartamos la posibilidad de que con el transcurrir del tiempo se agregaran otros significados más sobre la base de los significados primigenios.

Durante el análisis determinamos que algunos símbolos son variantes de otros elaborados de diferente manera, tales como la línea ondulada y el zig-zag, la greca y la espiral, la línea escalonada y la línea curva (Figura 26). Esto nos lleva a la conclusión de que el significado inicial era único para cada símbolo de las parejas enunciadas. Con el tiempo los significados podían diferenciarse 
creando símbolos distintos, pero, según creemos, su significado "básico" permanecía en ambos. Tomemos como ejemplo la línea ondulada y zig-zag. Ambos inicialmente significaban "agua" pero después adquirieron, por analogía, los significados de lluvia, serpiente o relámpago. La línea ondulada se empezó a utilizar más para expresar agua terrestre, mientras que el zig-zag para representar agua celeste. Sin embargo, los significados podían ser intercambiados entre sí. Como un ejemplo más tenemos el caso de la greca escalonada y la espiral. Su significado inicial es posible que era "crecimiento y creación en movimiento" pero, después adquirieron significados como el agua, el viento, la serpiente, el centro de la Madre Tierra. Como podemos ver, todos los significados posteriores están dentro del patrón semántico inicial. Arriba hemos sugerido que la greca estaba relacionada con la tierra mientras que la espiral con el cielo ya que coexistían en parelelo y debían tener algún elemento que los diferenciara. Y por último, el caso de la línea curva y la línea escalonada de un peldaño. Estos símbolos presentan dificultades en el análisis de su significado inicial, pero hemos determinado que en la cerámica de Izapa representaban "torrente de agua celeste". Lo enigmático en estos símbolos es su forma. ¿Cuál era su significado inicial? ¿Por qué tenían la forma de escalón? ¿Qué otros significados tenían?

Después de analizar el significado de los símbolos en la cerámica de Izapa tenemos ocho símbolos acuáticos y cuatro terrestres, así que podemos claramente relacionar la alfarería de esta ciudad (y la alfarería en general) con los dos aspectos naturales más importantes para el agricultor: el agua y la tierra. Lo que demuestra la exitencia de un culto agricola en Izapa (Lowe, Lee y Martínez E., 2000: 317). A eso se le suma el hecho de que las creencias básicas en Izapa se concentran en una especie de adoración a la naturaleza, o en una veneración o súplica a los Dioses (Proskouriakoff en Lowe, Lee y Martínez E., 2000: 320). La lluvia y su potencialidad generadora y de fertilidad era una de las preocupaciones religiosas más importantes de los izapeños (Moral del,
2000: 83). La propia alfarería, como lo considera Thomas Lee, es una alegoría de la vida agrícola pues el barro, con el que se crea la cerámica, es justamente producto de la mezcla del agua con la tierra (Lee, comunicación personal, 2009). También sabemos que la alfarería estaba presente en muchas ceremonias religiosas relacionadas con este tipo de cultos agrícolas, mismos que a su vez eran el principal estímulo para el desarrollo de los símbolos en la antigüedad.

Comovemos, el complejo cerámico de Izapa es sin duda una fuente importante para observar el origen, desarrollo y significado de los símbolos en general. Con este trabajo tratamos de abarcar todos los significados de todos los símbolos. Sin embargo, reconocemos que hay algunos símbolos cuyo significado requiere de más estudios pues, por el momento, se muestran difíciles de comprender. ${ }^{5}$

\section{Notas}

${ }^{1}$ Como los trabajos de Gareth Lowe, Rafaél Orellana, Jacinto Quirarte, Garth Norman, Julia Guernsey, entre otros.

2 Seguimos los nombres de las fases, utilizados en la bodega de la Fundacion Arqueológica Nuevo Mundo, A. C.

${ }^{3}$ Las imágenes de las estelas fueron tomadas del artículo: "Redrawing the Izapa Monuments", de John E. Clark y Ayax Moreno (2007).

${ }^{4}$ Podemos suponer como hipótesis que dichos símbolos se pueden considerar como "básicos", ya que aparecen primero, y la mayoría de ellos se repite en la cerámica del Preclásico que proviene de la región del río Grijalva (ver ilustraciones en Donne Bryant, Douglas, John E. Clark, and David Cheetham, 2005) y tienen mucha similitud en su imagen gráfica con la de Izapa, lo que nos habla sobre la existencia en el Chiapas Preclásico de un conjunto básico de símbolos, entre los cuales se encontraban los símbolos mencionados arriba.

${ }^{5}$ No quisiera terminar este trabajo sin agradecer a todas aquellas personas que me auxilaron en su elaboración. 
Al profesor Thomas Lee, quien durante todo el tiempo siempre me brindó su noble ayuda, sus atinados consejos y su valioso tiempo. A John Clark, Lyneth Lowe, Lourdes Morales Moreno y el mismo Thomas Lee por abrirme generosamente las puertas de la Fundación Arqueológica Nuevo Mundo. Y a Artemio Villatoro Vera por su importante apoyo técnico.

\section{Bibliografia}

Aguilera, Sabina (2007), "Mirando a través del espejo, recordando el camino primigenio. Un análisis iconográfico a la luz de la mitología y el ritual de los Tarahumaras", en: Indiana ním. 24, Berlin: Ibero-Amerikanisches Institut Preussischer Kulturbesitz, pp. 235-259.

Bauer, Wolfgang, Irmtraud Dümotz y Sergius Golowi (1998), Enciklopedia simvolov, Moscú: KRON-PRESS, [Traducción de Lexicon der Symbole].

Biedermann, Hans (1996), Enciklopedia simvolov, Moscú: Editorial Respublika, [Traducción de Knaurs Lexikon der Symbole, Munchen: Droemer Knaur, 1989].

Clark E., John and Ayax Moreno, (2007), "Redrawing the Izapa monuments", en Archaelogy, Art, and Ethnogenesis in Mesoamerican Prehistory: Papers in Honor of Gareth W. Lowe. Papers of the New World Archaeological Foundation, núm. 68, NWAF, Provo, Utah, EUA: Brigham Young University, pp. 277-321.

Donne Bryant, Douglas, John E. Clark, and David Cheetham (editors) (2005), Ceramic Sequence of the Upper Grijalva Region, Chiapas, México, Papers of the New World Archaeological Foundation, núm. 67, Part 1 and Part 2, Provo, Utah, EUA: Brigham Young University.

Ekholm, Susanna M. (1969), Mound 30 and the Early Preclasic ceramic sequence of Izapa, Chiapas, Mexico, Papers of the New World Archaeological Foundation, núm. 25, Provo, Utah, EUA: Brigham Young University.

Girard, Rafaél (1949), Los Chortis ante el problema maya. Historia de las culturas indigenas de America, desde su origen hasta hoy, México: Editorial Cultura.
Golan, Ariel (1994), Mif i simvol, Moscú: Editorial Nauka [Traducción de Myth and Symbol. Symbolism in Prehistoric Religions, Tarbut. Jerusalem],.

Grieder, Terence (1987), Origenes del Arte Precolombino, México: C.F.E.,. [Traducción de Origins of the Pre-Columbian Art. 1982. University of Texas Press, Austin].

Guernsey Julia (2006), Ritual and Power in the Stone: The Performance of Rulership in Mesoamerican Izapan-Style Art, EUA.: University of Texas Press.

Johansson K., Patrik (2007), "El agua y el fuego en el mundo náhuatl prehispánico", en Arqueología Mexicana, núm. 88. México: I.N.A.H.,. pp. 78-83.

Kolpakova, Alla (2008), "El símbolo del rombo en los bordados de los mayas de Chiapas", en: Estudios del Patrimonio Cultural de Chiapas, Universidad de Ciencias y Artes de Chiapas, Tuxtla Gutiérrez, Chiapas, México, pp. 279-295.

Lee, Thomas A. Jr. (1973), "Secuencia de fases post-formativas de Izapa, Chiapas, México", en Estudios de Cultura Maya, núm. 9, México: Centro de Estudios Mayas, UNAM, pp. 75-84.

López Austin, Alfredo (2002), Breve historia de la tradición religiosa mesoamericana, México: UNAM.

Lowe, Gareth W., Thomas A. Lee Jr., y Eduardo Martínez Espinosa (2000), Izapa: una Introducción a las ruinas y los monumentos, Fundación Arqueológica Nuevo Mundo, A. C., Documento núm. 31, Tuxtla Gutiérrez, Chiapas, México: CONECULTA, [Traducción de Izapa: An Introduction to the Ruins and Monuments].

Magni, Caterina (2008), "El glifo en tres dimensiones. Agua y fuego: un Leitmotiv del simbolismo olmeca", en Olmeca: balance y perspectivas. Memoria de la Primera Mesa Redonda, Tomo l, México: Instituto de Investigaciones Estéticas, UNAM,, pp. 245-265.

Martínez del Sobral, Margarita (2000), Geometría Mesoamericana, México: F.C.E.

Miller, Mary and Karl Taube (2004), An Illustrated Dictionary of the Gods and Symbols of Ancient Mexico and the Maya, London: Thames and Hudson. 
Moral del, Raúl (2000), "Izapa”, en Las culturas de Chiapas en el periodo prehispánico, México: CONECULTA-CONACULTA, pp. 61-87.

Paulinyi, Zoltán (2007), "La tierra como ser viviente en el arte teotihuacano", en Indiana, núm. 24, Berlin: IberoAmerikanisches Institut Preussischer Kulturbesitz, pp. 317-339.

Pye E. Mary and Gerardo Gutiérrez (2007), "The Pacific Coast trade route of Mesoamerica: iconographic connections between Guatemala and Guerrero", en Archaelogy, Art, and Ethnogenesis in Mesoamerican Prehistory: Papers in Honor of Gareth W. Lowe, Papers of the New World Archaeological Foundation, núm. 68, NWAF, Provo, Utah, EUA: Brigham Young University, , pp. 229-247.

Quirarte, Jacinto (2007), "Revisiting the relationship between Izapa, olmec, and maya art", en Archaelogy, Art, and Ethnogenesis in Mesoamerican Prehistory: Papers in Honor of Gareth W. Lowe, Papers of the New World Archaeological Foundation, núm. 68, NWAF, Provo, Utah, EUA: Brigham Young University, pp. 247-277.

Ribakóv, Borís (1981), Yazichestvo drevnij slavian, Moscú: Editorial Nauka

\section{Lista de Ilustraciones}

Figura 1. Mapa del Istmo Mayor (Lowe, Lee y Martínez E., 2000).

Figura 2. Tepalcates con símbolos de la Fase Izapa-Ocós (ca. 1500-1200 a.C.). Las figuras 2.a y f son fotos de Alla Kolpakova; las figuras 2.b-e son de Ekholm (1969: 28, 33 y 30).

Figura 3. Tepalcates con símbolos de la Fase Izapa-Cuadros (ca. 1200-1000 a. C.). Las figuras 3.a-i y k son fotos de Alla Kolpakova; las figuras 3.jy 1 son de Ekholm (1969: 43 y 49).

Figura 4. Tepalcates con símbolos de la Fase IzapaJocotal (ca. 1000-850 a.C.). Las figuras 4.a-d, f, g y i son fotos de Alla Kolpakova; las figuras 4.e y h son de Ekholm (1969: 56 y 63).
Figura 5. Tepalcates con símbolos de la Fase Izapa-Duende (ca. 850-650 a.C.). Las figuras 5.a, c-g son fotos de Alla Kolpakova; las figuras 5.b y h son de Ekholm (1969: 75 y 85).

Figura 6. Tepalcates con símbolos de la Fase Izapa-Escalón (ca. 650-450 a. C.) Las fotos son de Alla Kolpakova.

Figura 7. Tepalcates con símbolos de la Fase Izapa-Escalón-Frontera (ca. 650-300 a. C.) Las fotos son de Alla Kolpakova.

Figura 8. Tepalcates con símbolos de la Fase Izapa-Guillén (ca. 300-50 a. C.). Las figuras 8.a, b, d-h son fotos de Alla Kolpakova; las figuras 8.c y i son de Lowe, Lee y Martínez E., (2000: 172).

Figura 9. Vasija con símbolos de la Fase Izapa-Hato (ca. 50 a. C.-100 d. C.) (Lowe, Lee y Martínez E., 2000: 178).

Figura 10. Tepalcates y vasija con símbolos de la Fase Izapa-Itstapa (ca. 100-250 d. C). La figura 10.a es de Lee (1973: 86); las figuras 10.b-e son fotos de Alla Kolpakova.

Figura 1l. Tepalcates y vasija con símbolos de la Fase Izapa-Jaritas (ca. 250-400 d.C.) Las figuras 11.a-g, i y k-n son fotos de Alla Kolpakova; la figura 11.h es foto de Alla Kolpakova del negativo del archivo del NWAF; la Figura 11.j es de Lee (1973: 87).

Figura 12. Tepalcates con símbolos de la Fase Izapa-Kato (ca. 400-500 d.C.). Las figuras 12.a-e son fotos de Alla Kolpakova; la figura 12.f es foto de Alla Kolpakova del negativo del archivo del NWAF.

Figura 13. Tepalcates con símbolos de la Fase Izapa-Loros (ca. 500-600 d.C.) Las fotos son de Alla Kolpakova.

Figura 14. Tepalcates y vasijas con símbolos de la Fase Izapa-Metapa (ca. 600-700 d.C.) Las figuras 14.a, b, d y e son fotos de Alla Kolpakova; la figura 14.c es foto de Alla Kolpakova del negativo del archivo del NWAF; la figura 14.f es de Lowe, Lee y Martínez E., (2000: 192).

Figura 15. Tepalcates con símbolos de la Fase Izapa-Peistal (ca. 700-900 d.C.). Las fotos son de Alla Kolpakova.

Figura 16. Tepalcates y vasijas con símbolos de la Fase Izapa-Remanso (ca. 900-1200 d.C.). Las figuras 16.a-g, 
i, j, k y m son fotos de Alla Kolpakova; la figura 16.1 es foto de Alla Kolpakova del negativo del archivo del NWAF; la figura 16.h es de Lee (1973: 94).

Figura 17. Representación de lluvia en el Relieve 1, Chalcatzingo, Morelos (Magni 2008: 255).

Figura 18. Representación de nubes y lluvia en la Estela 21 de Izapa, Chiapas (Clark y Moreno, 2007: 300).

Figura 19. Representación de agua y nubes en la Estela 1 de Izapa, Chiapas (Clark y Moreno, 2007: 282).

Figura 20. Representación de nubes y lluvia en la Estela 26 de Izapa, Chiapas (Clark y Moreno, 2007: 306).

Figura 21. Representación de agua en la Estela 67 de Izapa, Chiapas (Clark y Moreno, 2007: 315).

Figura 22. Representación de nube en forma de "S" y de lluvia como "punto colgante" en el Monumento 31 de Chalcatzingo, Morelos (Pye y Gutiérrez, 2007: 236).

Figura 23. Representación de nube en forma de "S" y de lluvia en forma de líneas paralelas verticales, Teopantecunitlan (Pye y Gutiérrez, 2007: 236).

Figura 24. Representación de agua en la Estela 5 de Izapa, Chiapas (Clark y Moreno, 2007: 288).

Figura 25. Tabla comparativa de los símbolos que seguimos durante todas las fases de la secuencia de cerámica de Izapa.

Figura 26. Diferentes maneras de representar el mismo símbolo de acuerdo con la equivalencia de las figuras angulares con las circulares.

Figura 27. Tabla de significados propuestos para los símbolos en la cerámica de Izapa. 


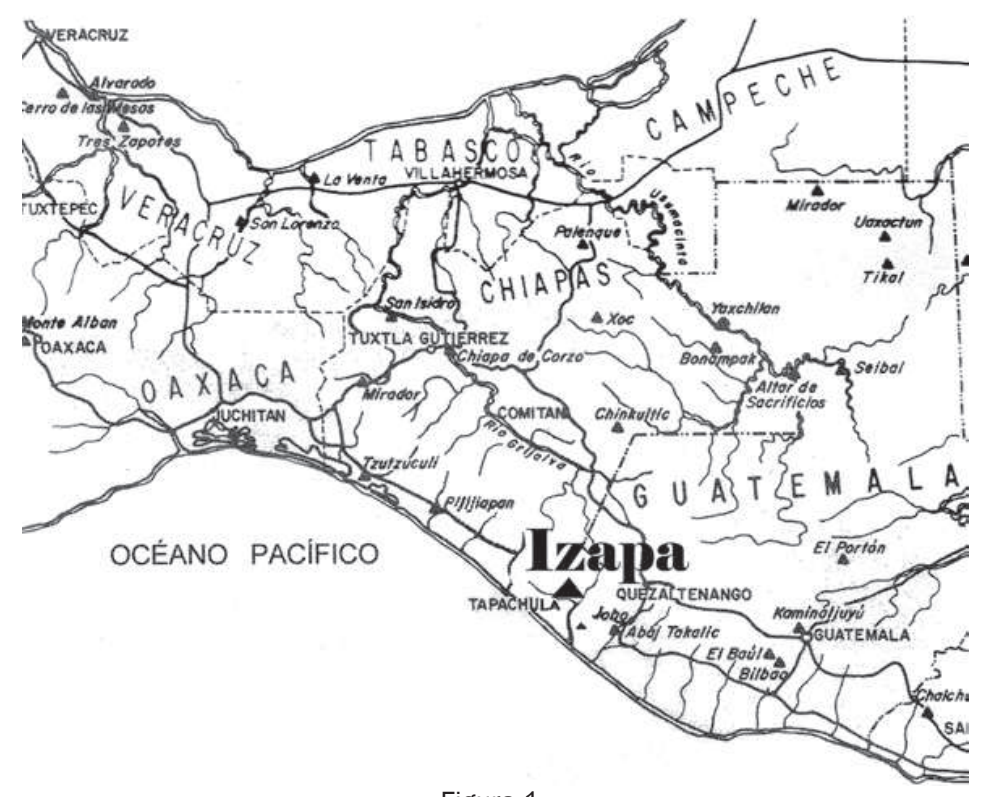

Figura 1

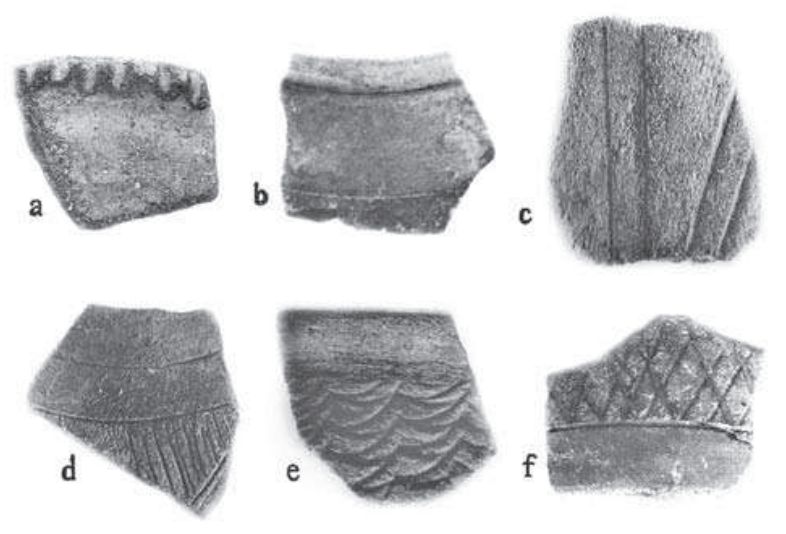

Figura 2 

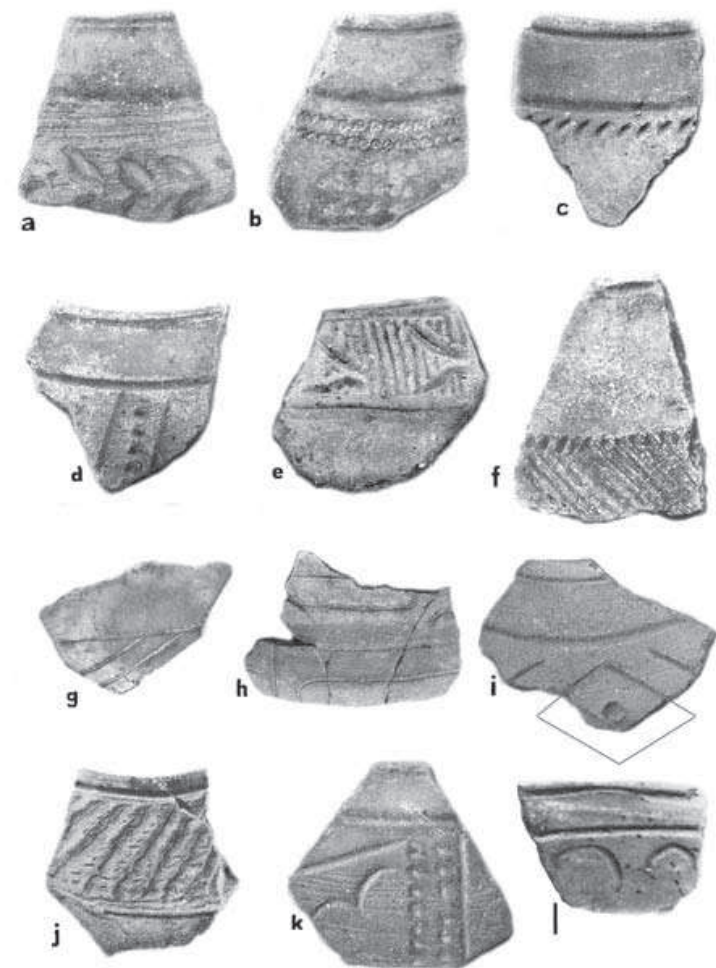

Figura 3
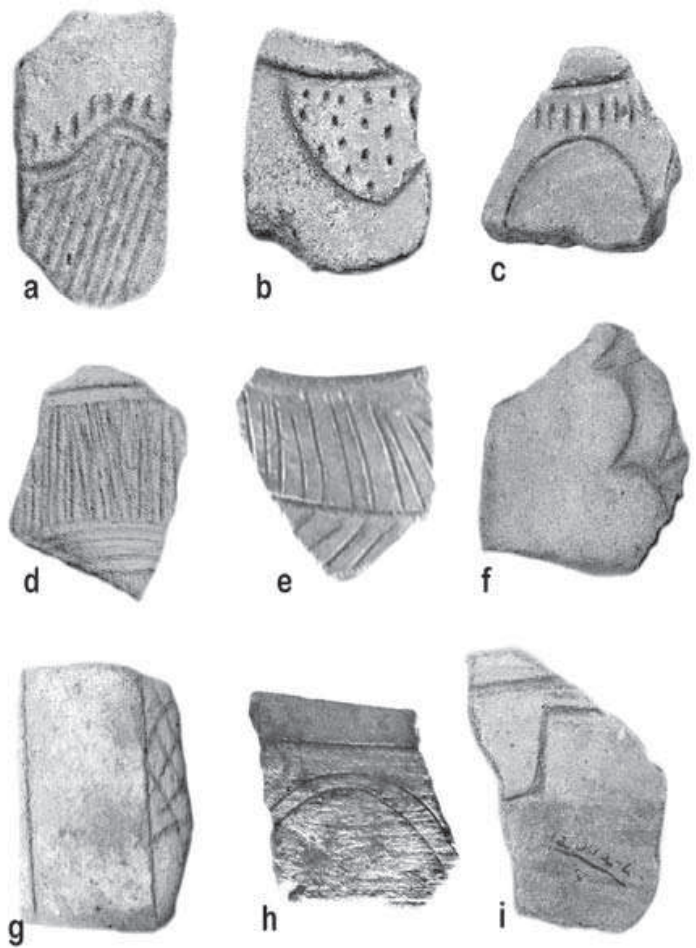

Figura 4 

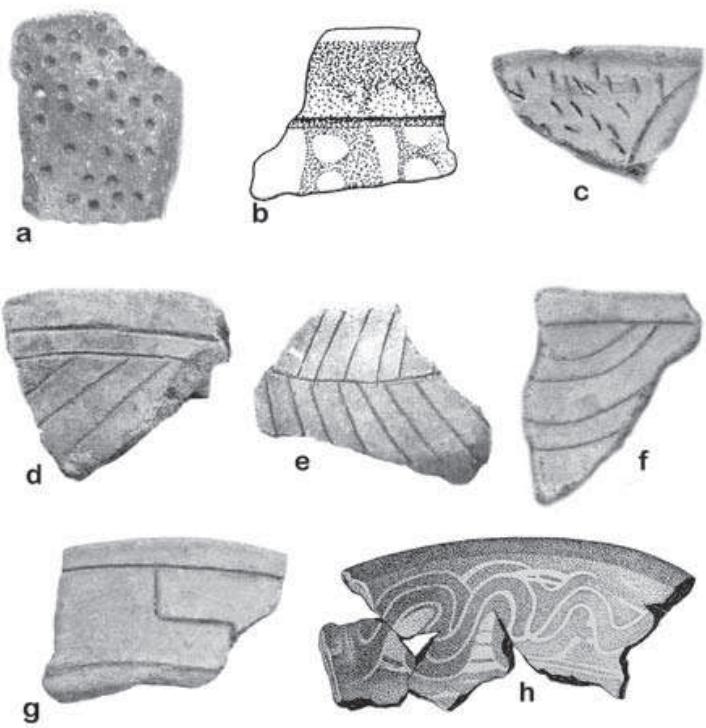

Figura 5
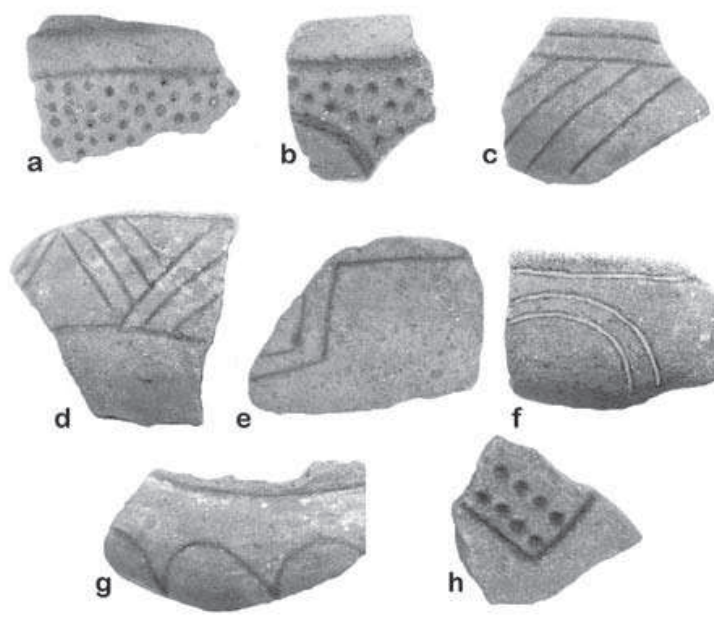

Figura 7

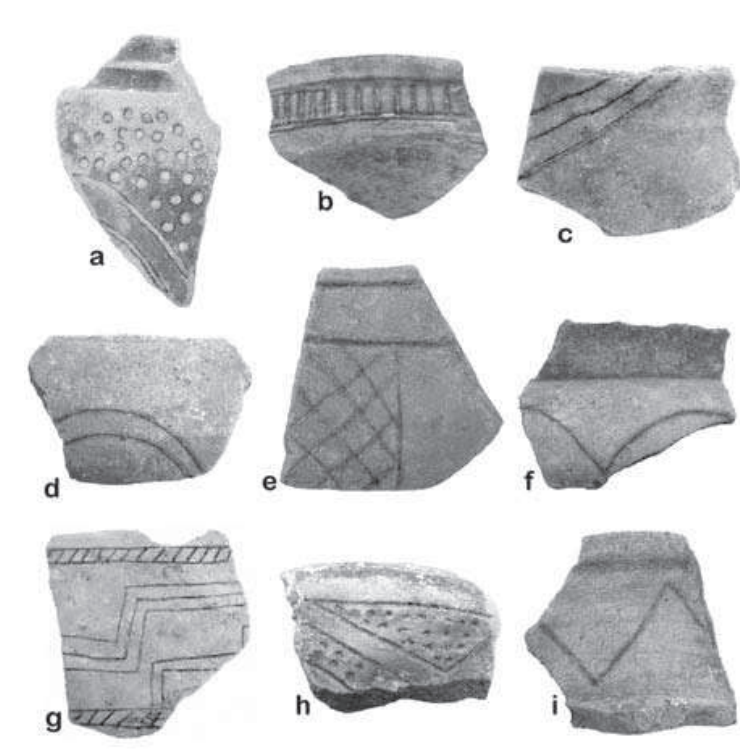

Figura 6
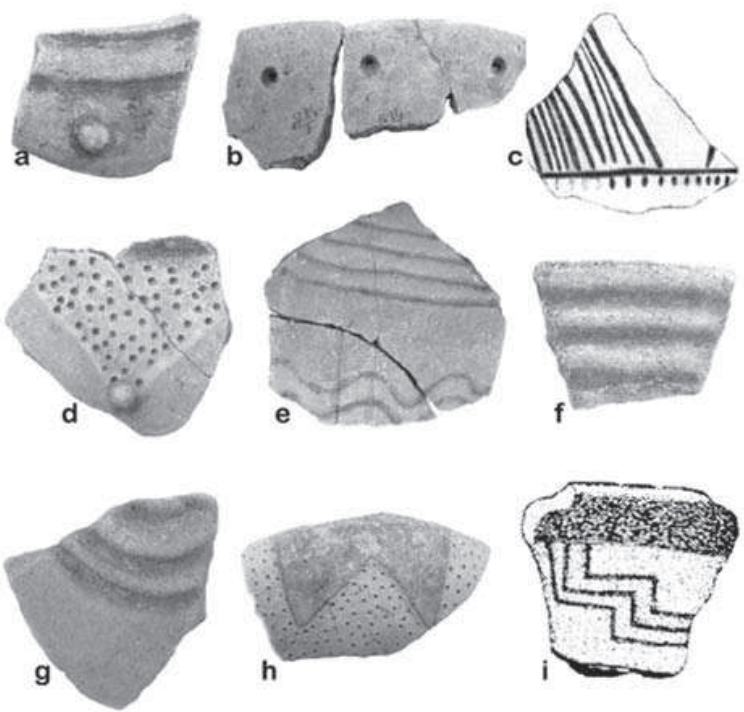

Figura 8 


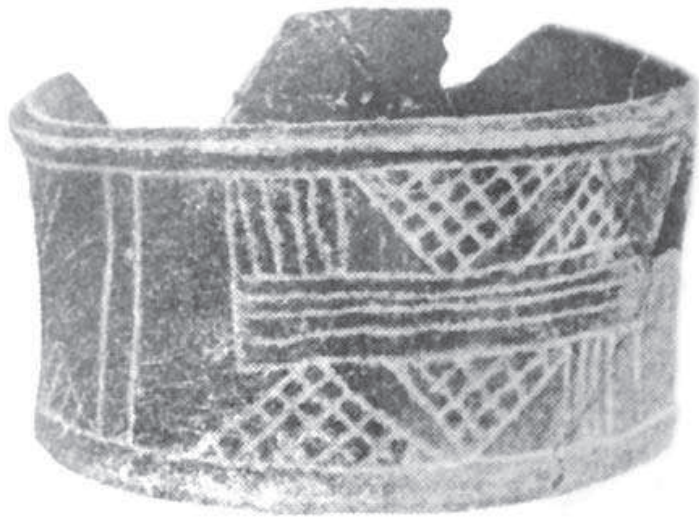

Figura 9
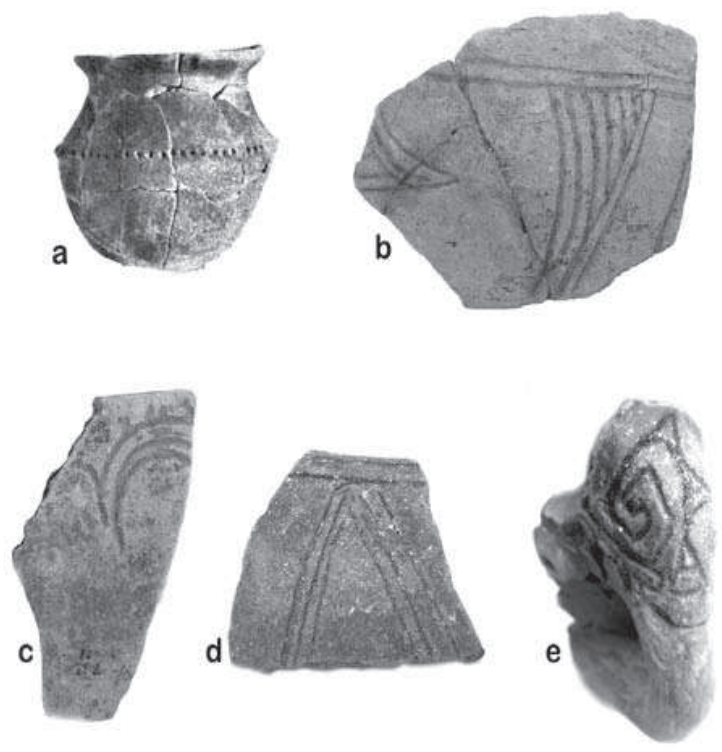

Figura 10 

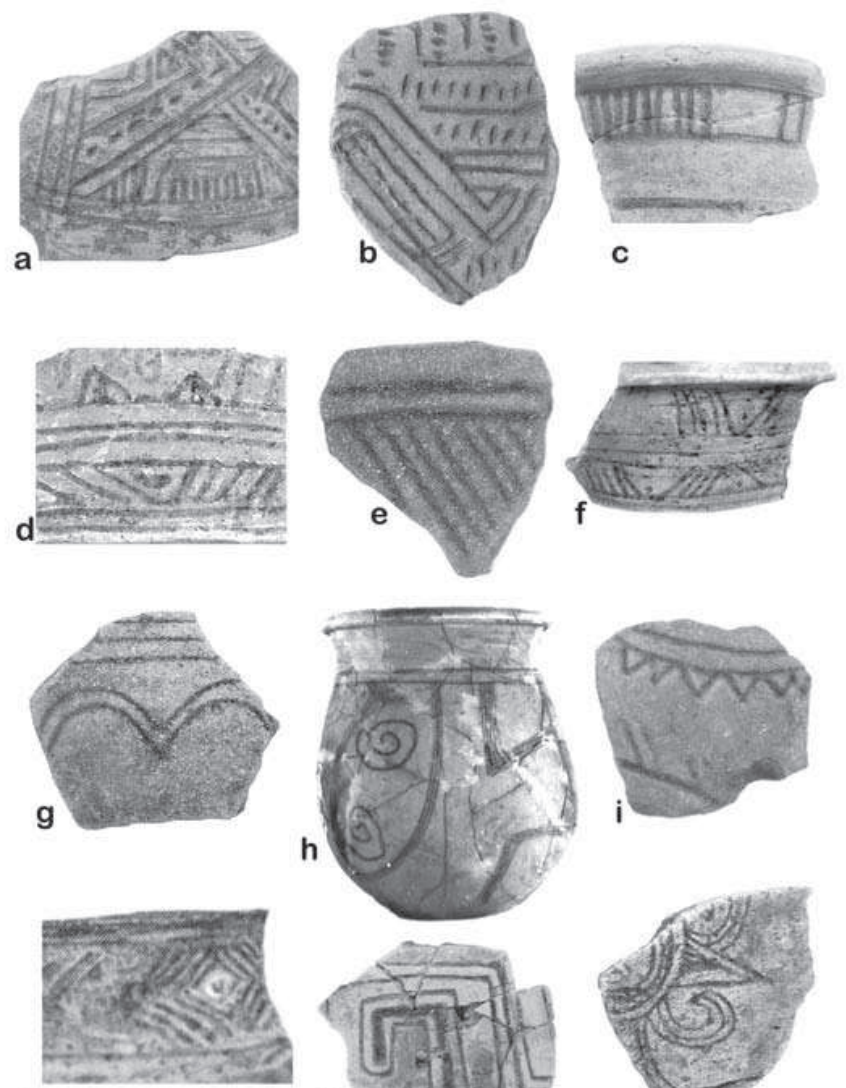

j
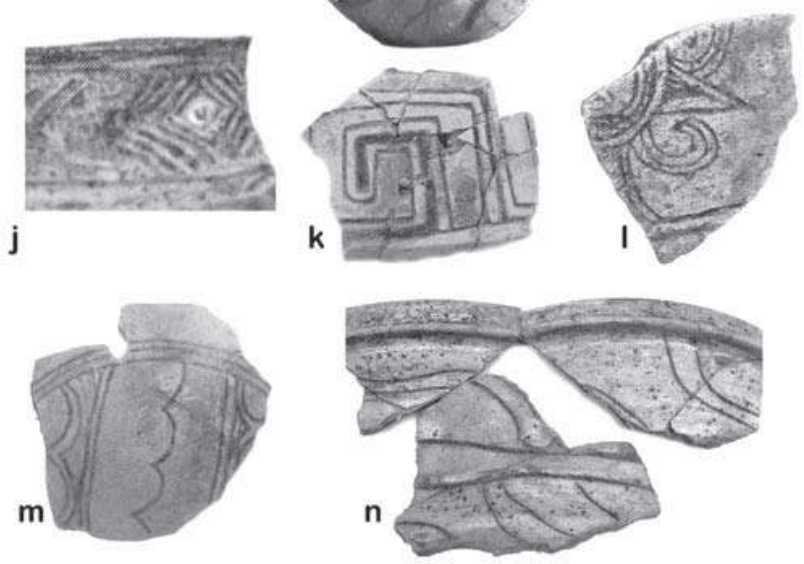

Figura 11

Revista LiminaR. Estudios sociales y humanísticos, año 7, vol. VII, núm. 2, diciembre de 2009, Tuxtla Gutiérrez, Chiapas, México. ISSN: 1665-8027 


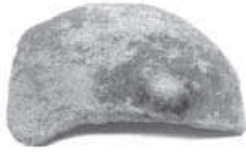

a

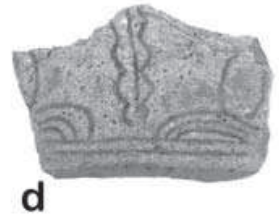

d
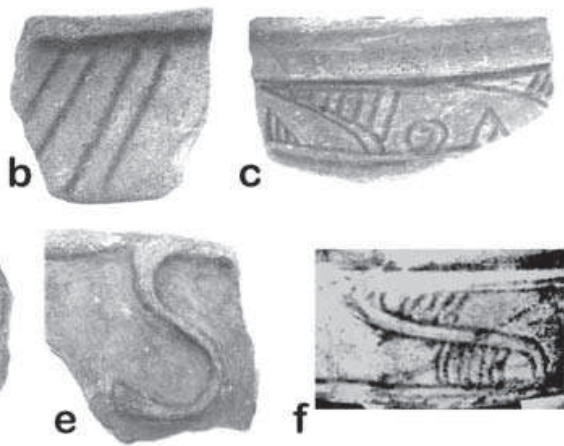

Figura 12
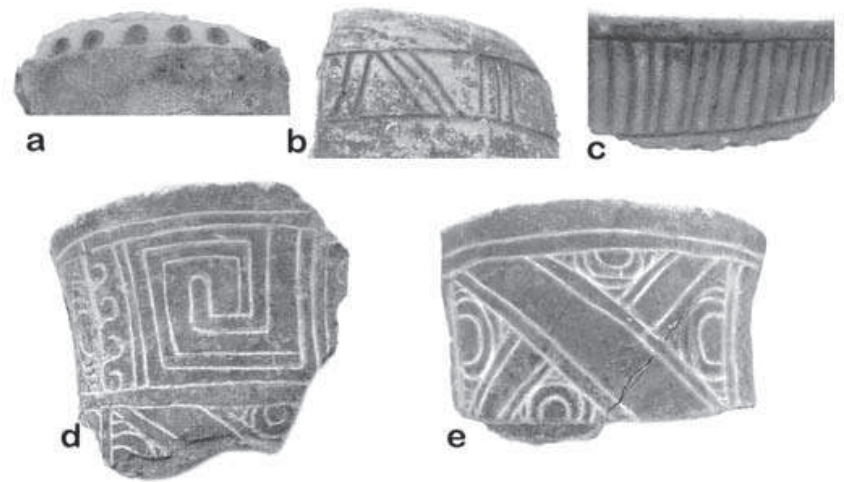

Figura 13
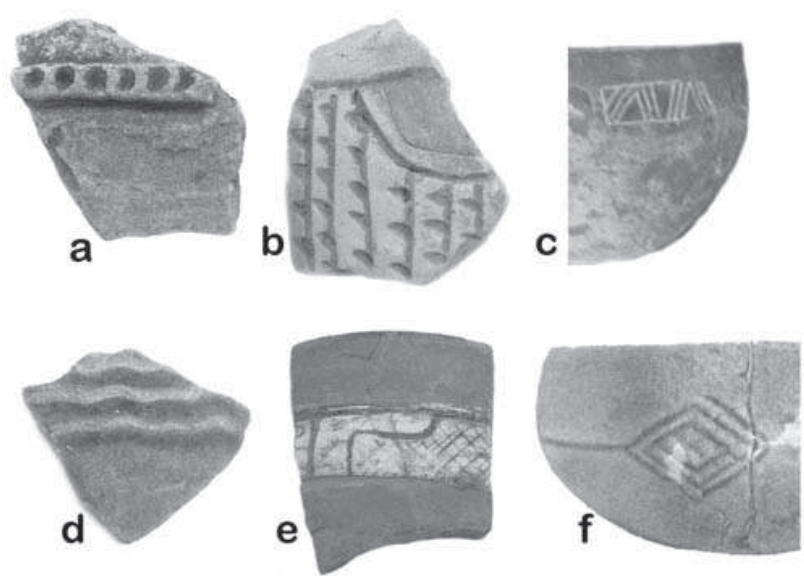

Figura 14 

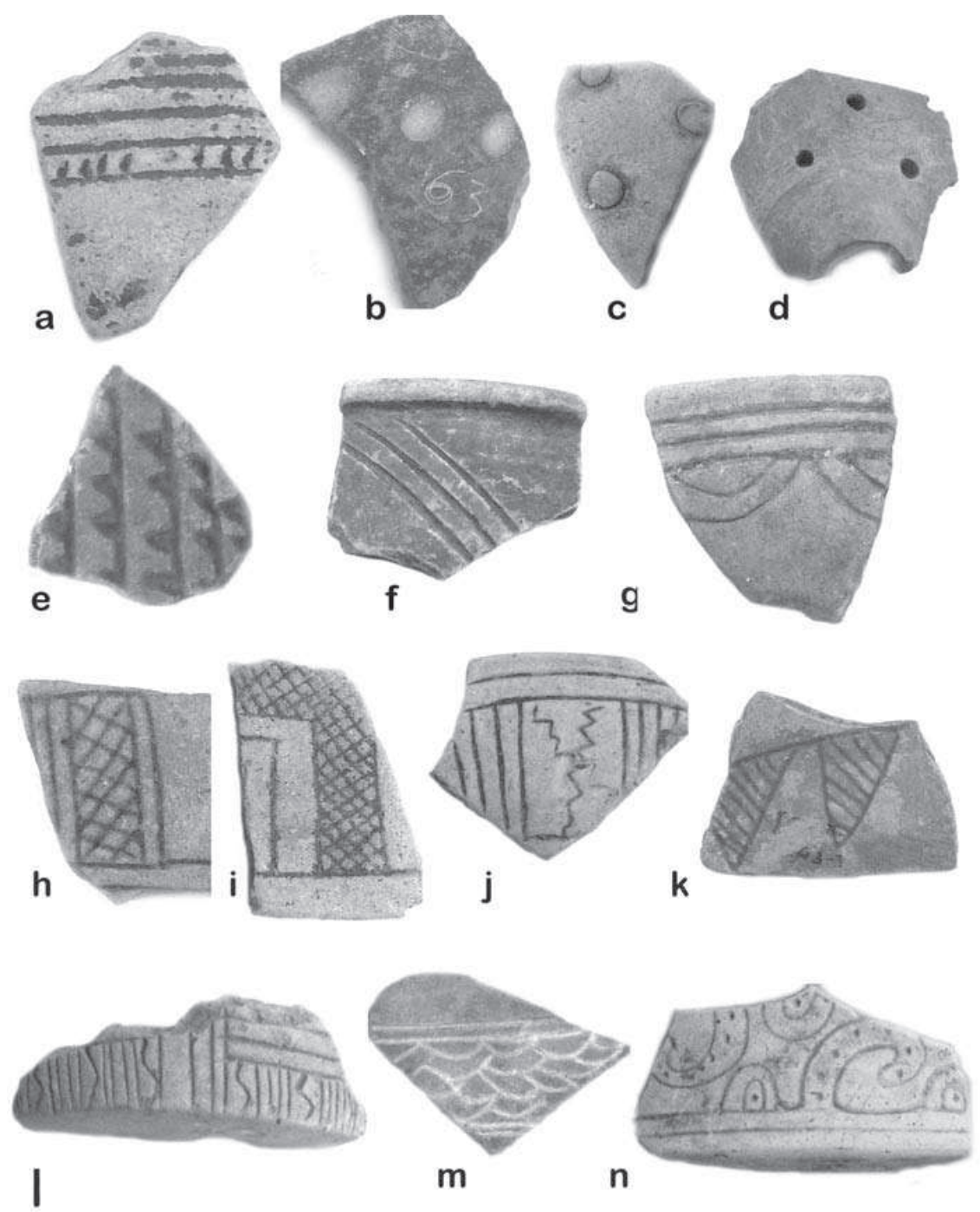

Figura 15

Revista LiminaR. Estudios sociales y humanísticos, año 7, vol. VII, núm. 2, diciembre de 2009, Tuxtla Gutiérrez, Chiapas, México. ISSN: 1665-8027 

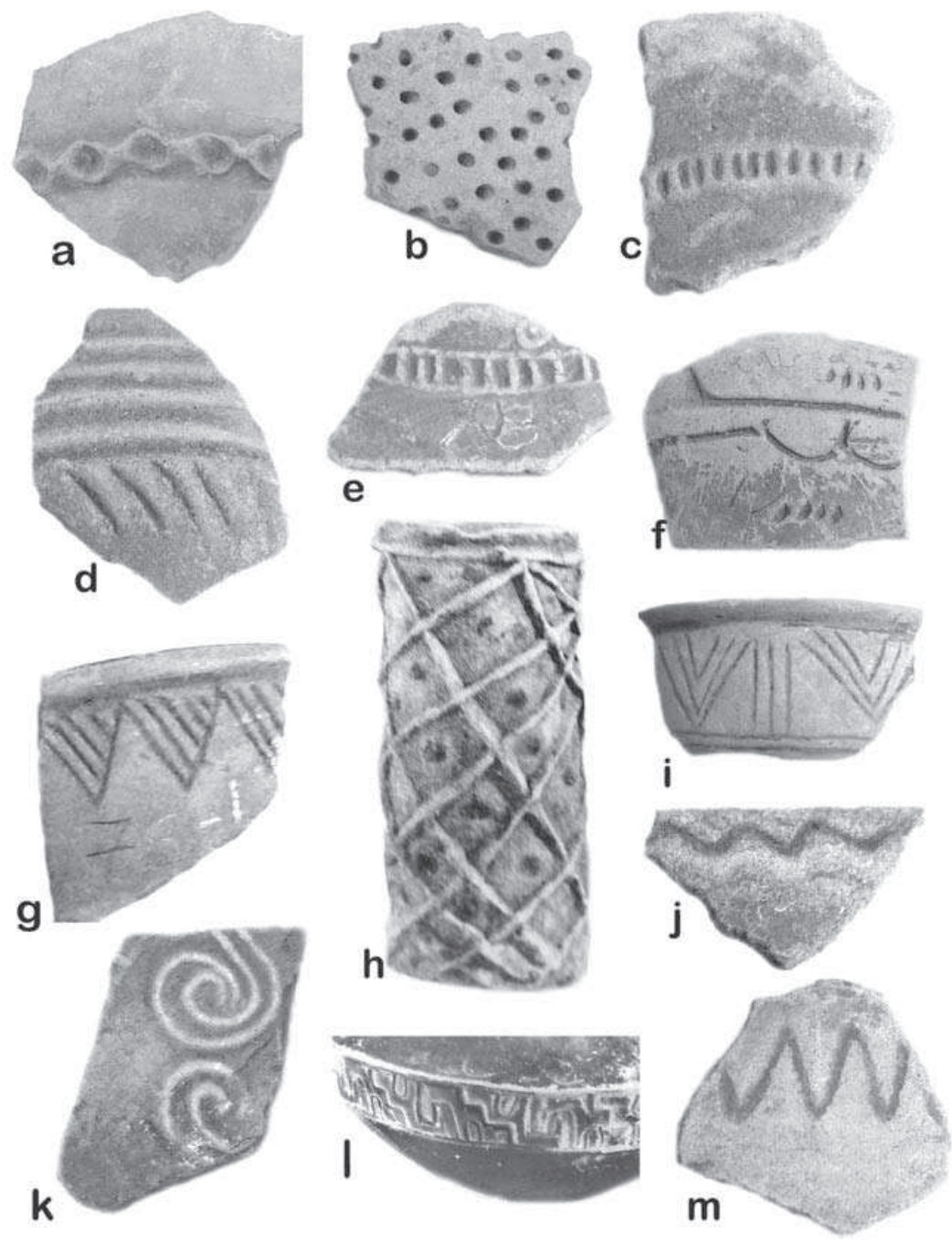

Figura 16 


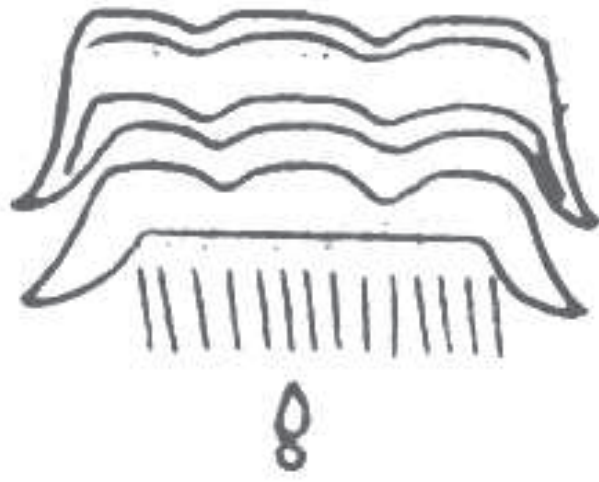

8

8

Figura 17

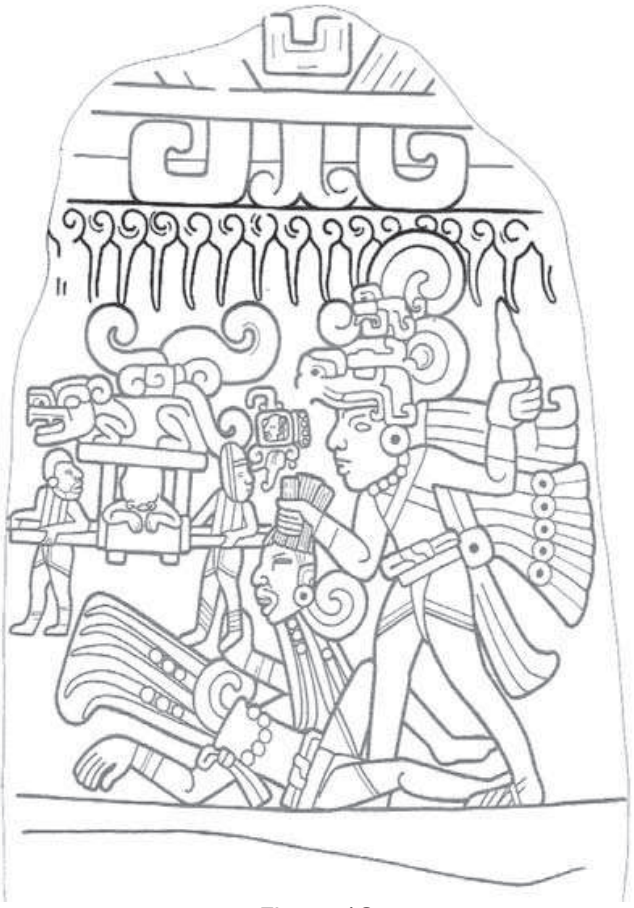

Figura 18

Revista LiminaR. Estudios sociales y humanísticos, año 7, vol. VII, núm. 2, diciembre de 2009, Tuxtla Gutiérrez, Chiapas, México. ISSN: 1665-8027 


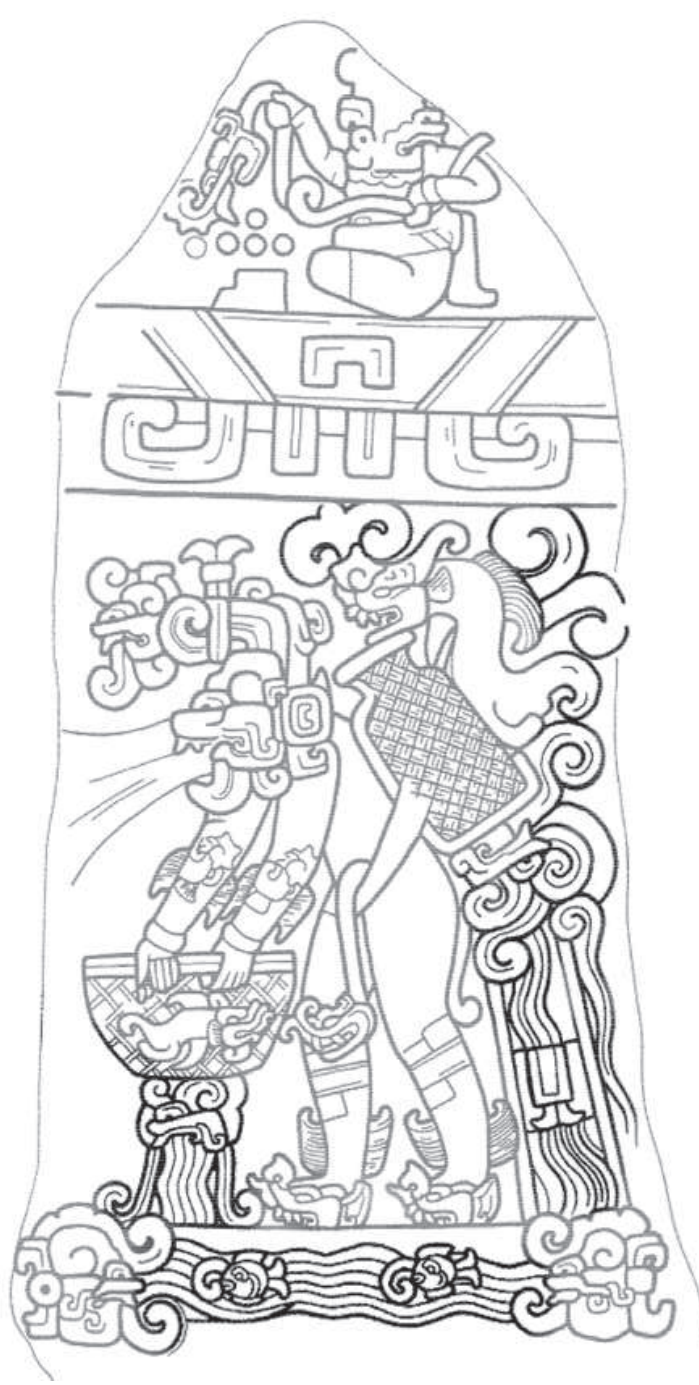

Figura 19

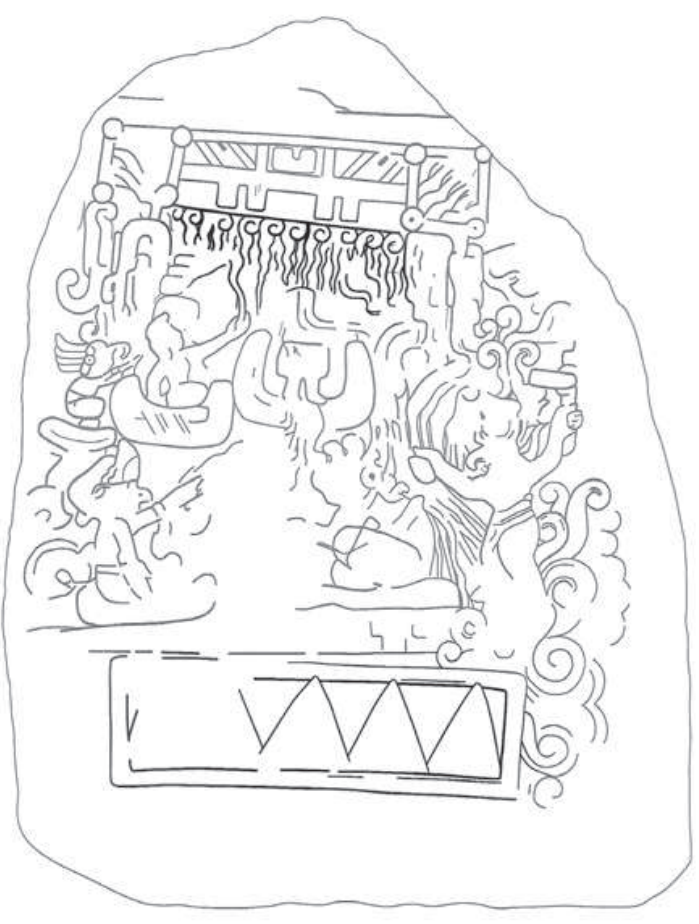

Figura 20 


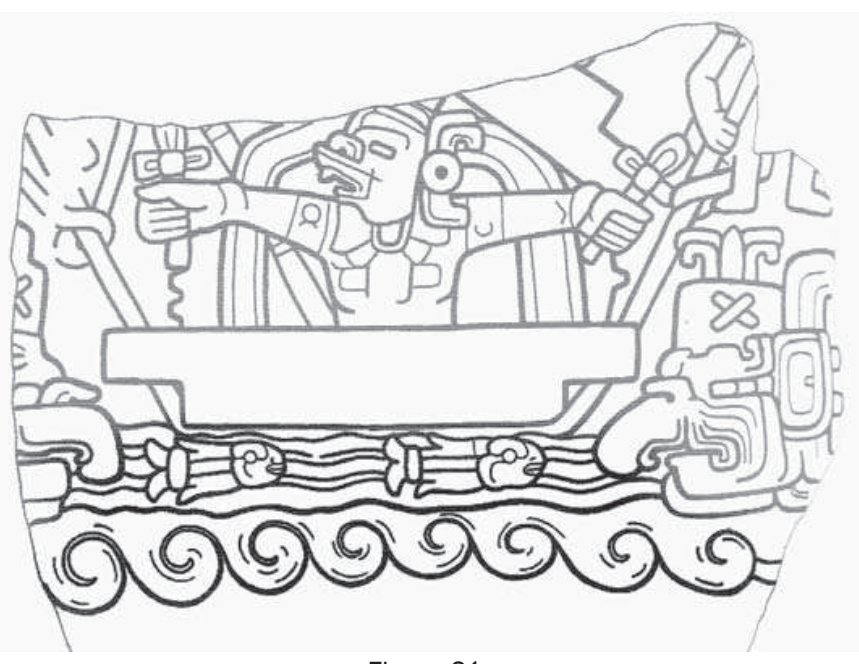

Figura 21

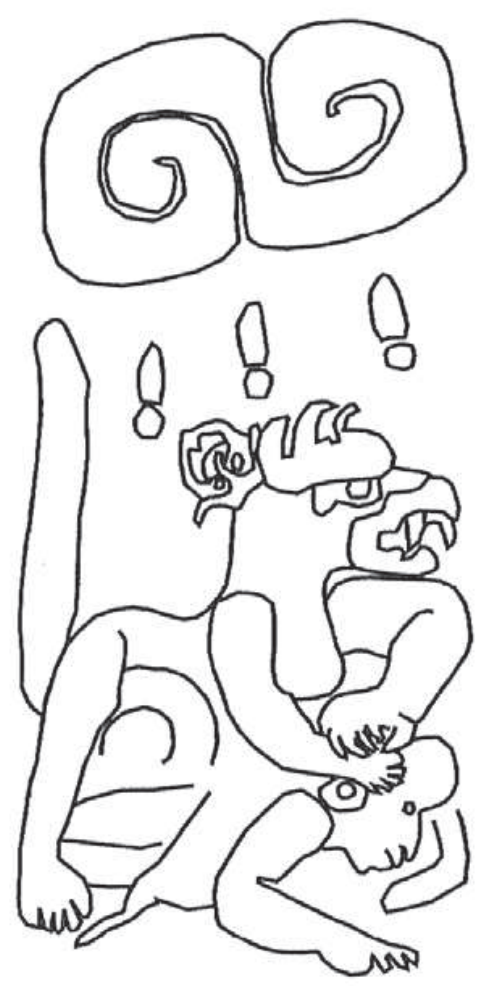

Figura 22 


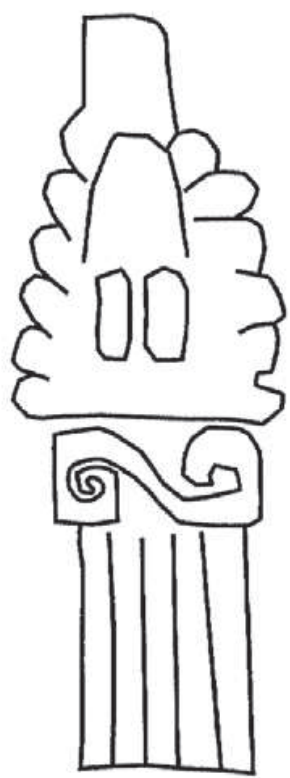

Figura 23

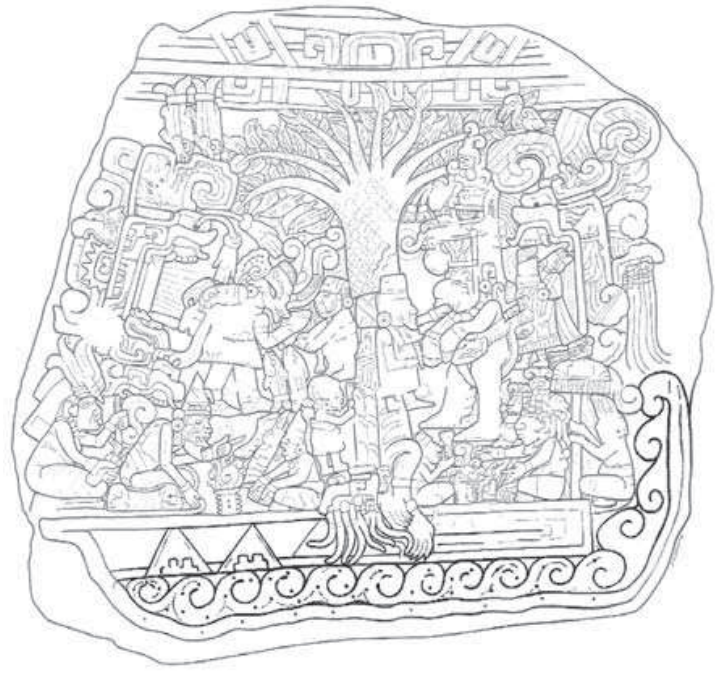

Figura 24

\begin{tabular}{|c|c|c|c|c|c|c|c|c|c|c|c|c|}
\hline FASE SIMBOLO & PUNTOS & $\begin{array}{l}\text { UNEAS } \\
\text { RECTAS }\end{array}$ & REJA & $\begin{array}{l}\text { MEDI0 } \\
\text { GiRCULO }\end{array}$ & ROMBO & $\begin{array}{l}\text { UNEA } \\
\text { ONDVUADA }\end{array}$ & TrRANGULO & $\begin{array}{l}\text { LNEA } \\
\text { ESCALOW } \\
\text { ADA }\end{array}$ & ZIG-ZAG & GRECA & ESPIRAL & $\begin{array}{l}\text { UNEA } \\
\text { CURVA }\end{array}$ \\
\hline $\begin{array}{l}\text { Ocós } \\
(1500-1200 \text { a. C. })\end{array}$ & (158 & 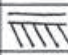 & $x$ & & & & & & & & & \\
\hline $\begin{array}{l}\text { Cuadros } \\
(1200-1000 \text { a.C. })\end{array}$ & $\because 08$ & IIIII & & $\frown$ & $\langle 0$ & 311 & & & & & & \\
\hline $\begin{array}{l}\text { Jocotal } \\
(1000-850 \text { a. C. })\end{array}$ & $\because 11 ! 1$ & मt) & $2 x x$ & \% & & & 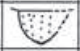 & $\bar{\Gamma}$ & & & & \\
\hline $\begin{array}{l}\text { Duende } \\
(850-650 \text { a.c. })\end{array}$ & !I! & IIII & & $\because$ & & Ras & & 5 & & & & \\
\hline $\begin{array}{l}\text { Escalon } \\
(650-450 \text { a. C. })\end{array}$ & $\because \because$ & IIIII & x & $\approx$ & & & 4 & & & & & \\
\hline 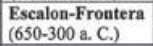 & $\because \because$ & 7ा7ा & & $\approx$ & & & $\because \%$ & $\exists$ & & & & \\
\hline $\begin{array}{l}\text { Guillién } \\
(300-50 \text { a. C.) }\end{array}$ & io: & 1111 & & E & & $\approx$ & $W$ & 世匀 & & & & \\
\hline $\begin{array}{l}\text { Hato } \\
\text { (50 a. C.-100 d.C) }\end{array}$ & & 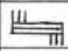 & $\infty$ & & & & W & III & & & & \\
\hline $\begin{array}{l}\text { Itstapa } \\
(100-250 \text { d. C.) }\end{array}$ & $\cdots$ & $\mathbb{Z} \mathbb{1}$ & & ถ & & & 4 & & & 58 & & 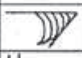 \\
\hline $\begin{array}{l}\text { Jaritas } \\
(250-400 \text { d. C) }\end{array}$ & י'י & $\overline{\Pi ा I}$ & & 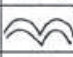 & $\Leftrightarrow$ & 3 & $\because$ & & & ज1 & (9) & \\
\hline $\begin{array}{l}\text { Kato } \\
(400-500 \text { d. C. })\end{array}$ & 0 & $71 \pi$ & & $\approx$ & & 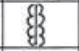 & $\mathbb{A}$ & & & & (9) 5 & ब㟧 \\
\hline $\begin{array}{l}\text { Loros } \\
\text { (500-600 d. C.) }\end{array}$ & $\bullet \bullet \bullet$ & $\mathbb{\mathbb { M }}$ & & (י) & & & & & & 國 & $k$ & \\
\hline $\begin{array}{l}\text { Metapa } \\
(660-700 \text { d. C. })\end{array}$ & $\bullet \bullet$ & $\mathbb{Z} \mathbb{N}$ & 浆 & 6 & - & $\approx$ & & $\Gamma$ & & & & \\
\hline $\begin{array}{l}\text { Peistal } \\
\text { (700-900 d. C.) }\end{array}$ & $\dot{0}$ & & 1 & $\Theta$ & & & $\mathbb{y}$ & & $\frac{4}{5}$ & & & $\zeta \mathbb{\Gamma}$ \\
\hline $\begin{array}{l}\text { Remanso } \\
\text { (900-1200 d. C.) }\end{array}$ & ச்'li' & $\overline{1111}$ & 㸒 & $\omega$ & & $\sim \Omega$ & v & & & רית & (c) & \\
\hline
\end{tabular}

Figura 25 


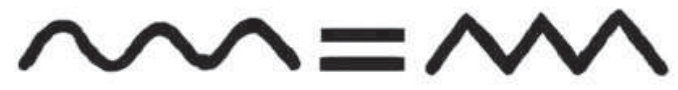

\section{Linea ondulada Zig-zag}

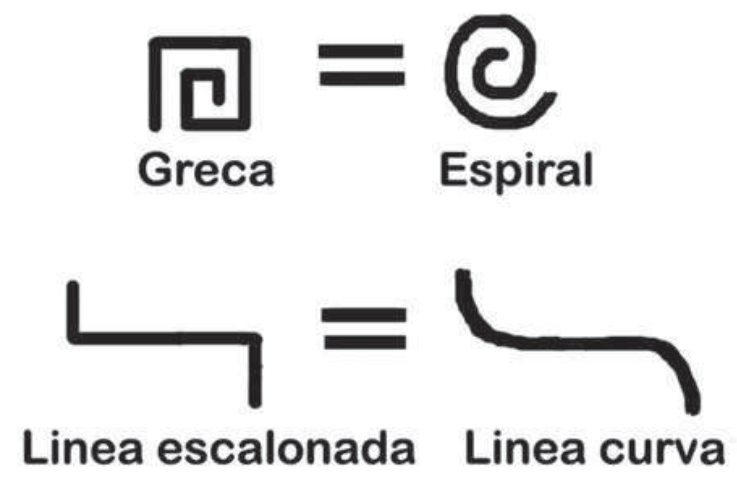

Figura 26

\begin{tabular}{|l|l|}
\hline Símbolo & \multicolumn{1}{c|}{ significado } \\
\hline & Semillas o gotas \\
\hline & Aielo y lluvia \\
\hline & Agua o serpiente \\
\hline
\end{tabular}

Figura 27 